\title{
An observation checklist for facility-based normal labor and delivery practices: The Galaa study
}

Hania Sholkamy

Nevine Hassanein

Mohamed Cherine

Amr Elnoury

Miral Breebaart

See next page for additional authors

Follow this and additional works at: https://knowledgecommons.popcouncil.org/departments_sbsr-rh How does access to this work benefit you? Let us know!

\section{Recommended Citation}

Sholkamy, Hania, Nevine Hassanein, Mohamed Cherine, Amr Elnoury, Miral Breebaart, and Karima Khalil. 2003. "An observation checklist for facility-based normal labor and delivery practices: The Galaa study," Monographs in Reproductive Health. Cairo: Population Council. 
Authors

Hania Sholkamy, Nevine Hassanein, Mohamed Cherine, Amr Elnoury, Miral Breebaart, and Karima Khalil 


\section{An Observation Checklist for Facility-Based Normal Labor and Delivery Practices: The Galaa Study}

Hania Sholkamy, Nevine Hassanein, Mohamed Cherine, Amr Elnoury, Miral Breebaart and Karima Khalil

MONOGRAPHS IN REPRODUCTIVE HEALTH

No. 5 
The Population Council seeks to improve the well-being and reproductive health of current and future generations around the world and to help achieve a humane, equitable, and sustainable balance between people and resources.

The Council, a nonprofit, non-governmental research organization established in 1952, has a multinational Board of Trustees; its New York headquarters supports a global network of regional and country offices.

Monographs in Reproductive Health is produced by the Reproductive Health Working Group housed in the Population Council Regional Office for West Asia and North Africa, 59 Misr-Helwan Agricultural Road, Maadi, Egypt. Views expressed herein are the sole responsibility of the authors.

(C) Copyright 2003

The Population Council

ISBN:

Authors: Hania Sholkamy, Nevine Hassanein, Mohamed Cherine, Amr Elnoury, Miral

Breebaart and Karima Khalil

Cover Design:

Printing Supervisor: 


\section{TABLE OF CONTENTS}

Preface IV

Abstract V V

Acknowledgments $\quad$ VI

I. Introduction 1

Why study facility practices for normal labor? 1

The study site $\quad 2$

This document 2

II. Study Objectives and Methods 2

Objectives 2

Data collection methods 3

Comparison of findings with best-practices 3

Methodological choices 3

III. The Research Process 4

Ethical review 4

Developing the checklist 4

Piloting the checklist 5

Training and preparing for data collection 5

Data collection 6

Findings $\quad 6$

IV. This Publication $\quad 7$

V. Categories of Comments 8

A. General comments $\quad 8$

B. Comments relating to specific questions 11

$\begin{array}{ll}\text { VI. Conclusion } & 18\end{array}$

$\begin{array}{ll}\text { References } & 19\end{array}$

Appendix A The Observation Checklist

Appendix B Grouping of Data Variables by Question Number

Appendix C Examples of Findings 


\section{PREFACE}

\section{Monographs in Reproductive Health}

Monographs in Reproductive Health aim at sharing research and analysis undertaken by members of the Reproductive Health Working Group with the wider research community. The Reproductive Health Working Group was established in 1988 as part of a Special Program on the health of women and children within the context of the family and community. The program was initiated by the Population Council's Regional Office for West Asia and North Africa (WANA). The Working Group includes professionals with specializations in anthropology, biostatistics, demography, medicine, public health and sociology, residing in various countries of the region.

The Working Group delineated three key issues which were considered central to women's reproductive health in the WANA region: first, women's physical health in terms of morbidity conditions related to the reproductive function; second, women's perceptions of their health and their dignity in relation to reproduction; and third, on the health service side, the quality of reproductive health services directed to women. The Working Group has been undertaking studies addressing these issues in countries of the region since 1989. Further research interests are currently emerging concerned with developing an intervention framework to improve reproductive health within primary care settings, and with investigating physicians' perceptions of women's health.

Monographs in Reproductive Health and the Policy Series in Reproductive Health are two complementary publications issued by the Reproductive Health Working Group. Papers in the Policy series in Reproductive Health reach out with frameworks, methodologies and evidence of research to policy makers, program managers and health advocates. They aim to contribute to the development of more holistic policy approaches to women's health. Monographs in Reproductive Health address researchers and students primarily, and aim to cross disciplinary lines. They represent original research, reviews of literature and theoretical discussions on subjects of interest to one discipline, either medical or social sciences, bringing concepts and results into the realm of understanding and interest of other fields. In this way the Monographs in Reproductive Health aim to contribute to the advancement of interdisciplinary approaches in research on women's reproductive health. 


\begin{abstract}
Globally, almost 515,000 women die every year from maternal causes related to pregnancy or childbirth (WHO, 2001). Most research understandably focuses on identifying high-risk cases or managing obstetric emergencies, in the attempt to reduce women's risk of dying of maternal causes. While facility practices for normal labor were extensively examined and revised in Europe and North America in the 1970s and 1980 s, very little is known about facility practices for normal labor in many parts of the developing world.
\end{abstract}

However, it is important for practitioners and policy-makers to know the nature and frequency of common facility practices for normal labor, for several reasons. Firstly, normal labor is the most common obstetric event. It constitutes the majority $(85 \%)$ of all deliveries globally. Secondly, it is also a very significant and influential event in women's lives. Moreover, of all maternal deaths that are due to bleeding after delivery (up to half of all maternal deaths), most of these happen to women who experienced a normal labor (Akins, 1994).

In Egypt, although $49 \%$ of all deliveries take place in facilities and $69 \%$ are assisted by medical providers (DHS, 2001), maternal mortality remains relatively high at 84 maternal deaths per 100,000 live births (MOHP, 2001). Substandard care has been identified by the Egyptian Ministry of Health and Population as the leading avoidable factor contributing to maternal deaths in Egypt. Through efforts such as the MOHPUSAID Healthy Mother Healthy Child program, much progress has been achieved regarding management of obstetric emergencies. However, facility practices for normal labor are unexplored and undocumented in Egypt.

The research team therefore felt that understanding practices for normal labor was an important and neglected area of study. With the support and collaboration of El Galaa hospital staff, the study "Hospital Practices for Normal Labor: The Relationship of Observed Practices to Evidence-based Medicine" was conducted in 2001, and yielded comprehensive and unexpected data. This publication presents one of the data collection tools, the observation checklist, developed by the multidisciplinary team of researchers. It was used to comprehensively document the labor and delivery experience of 176 women experiencing normal labor, at the busy obstetric teaching facility.

The observation checklist presented here yielded a large and detailed dataset. The team found it to be a very useful tool in documenting common facility practices. This booklet describes the process of developing the observation checklist. It also includes a critical analysis of its performance. The checklist itself is shown as it was used (Appendix A). This is followed by tables matching the findings with the checklist questions (Appendix B). Examples of findings are also included (Appendix C), illustrating the type of data collected. It is hoped that the team's experience will prove useful for others in the field of Safe Motherhood. 


\section{ACKNOWLEDGMENTS}

"Hospital Practices for Normal Labor: The Relationship of Observed Practices to Evidence-based Medicine" (also known as the Galaa Study) was conceptualized and conducted by two members of the Reproductive Health Working Group; a public health physician and a medical anthropologist, with four obstetricians, a neonatologist and a data manager. It was conducted with the support and collaboration of the staff of El Galaa Teaching Hospital. Twelve obstetricians from outside El Galaa conducted the observations and collected the data.

The study team is grateful to Dr. Nabil Younis for his guidance, insights and encouragement on this and other initiatives undertaken by the Reproductive Health Working Group. We also thank Dr. Oona Campbell for her comments on the checklist and its analysis and Dr. Abdelaziz al Shoubary who was instrumental in facilitating the research and providing insight and access to the research setting. We are also grateful to Dr. Suellen Miller for her review of this document. The support of the Undersecretary for Curative Services, Dr. Hassan al Qalla and the Director-General of Teaching Hospitals, Dr. Abdel Hamid Abaza has been a source of much encouragement to the team.

The pilot phase of the research was supported by the Social Research Center of the American University in Cairo. The study was supported by the Ford Foundation Cairo office, the Faculty of Health Sciences at the American University in Beirut, the Reproductive Health Working Group and the Population Council West Asia and North Africa Regional Office. 


\section{Introduction}

\section{Why study facility practices for normal labor?}

Globally, almost 515,000 women die every year from maternal causes related to pregnancy or childbirth (WHO, 2001). Most research understandably focuses on identifying high-risk cases or managing obstetric emergencies, in the attempt to reduce women's risk of dying of maternal causes. While facility practices for normal labor were extensively examined and revised in Europe and North America in the 1970s and 1980 s, very little is known about facility practices for normal labor in many parts of the developing world.

However, it is important for practitioners and policy-makers to know the nature and frequency of common facility practices for normal labor, for several reasons. Firstly, normal labor is the most common obstetric event. It constitutes the majority $(85 \%)$ of all deliveries globally. Secondly, it is a very significant and influential event in a woman's life. Moreover, of all maternal deaths that are due to bleeding after delivery (up to half of all maternal deaths), most of these happen to women who experienced a normal labor (Akins, 1994).

There is need to document facility practices for normal birth in Egypt. Facility-based births are increasing. Although $49 \%$ of all deliveries take place in facilities and $69 \%$ are assisted by medical providers (DHS, 2000), maternal mortality remains relatively high at 84 maternal deaths per 100,000 live births (MOHP, 2001). Substandard care has been identified by the Egyptian Ministry of Health and Population's most recent survey of maternal mortality as the leading avoidable factor contributing to maternal deaths. Improving obstetric care is a government priority and intensive country-wide training programs addressing obstetric emergencies are systematically conducted in partnership with various agencies. While much progress has been achieved regarding management of obstetric emergencies by programs such as the Healthy Mother Healthy Child Program (Healthy Mother/Healthy Child, 2000), facility practices for normal labor are undocumented in Egypt.

The research team therefore felt that understanding facility practices for normal labor was an important and neglected area of study. This publication presents one of the data collection tools, the observation checklist, developed by the multidisciplinary team of researchers. It was used to comprehensively document the labor and delivery experience of 176 women experiencing normal labor, at a busy obstetric teaching facility. It includes a semi-structured interview which was done to explore women's perceptions of their birthing experience. 


\section{The study site}

The hospital where the study was conducted is one of the largest specialized obstetric facilities in Egypt with a caseload of 20,000 deliveries annually. An average of 200 young doctors receive their training at the facility every year, and subsequently disseminate what they have learned to other service delivery settings. The study findings, documenting provider practices and women's perceptions, are of direct policy relevance to the hospital itself as well as to obstetricians, researchers and policy-makers in Egypt and elsewhere.

\section{This document}

This document presents the observation checklist which was used to record provider practices by direct observation and which yielded very comprehensive and detailed data on common provider practices in normal labor and delivery. Having this data for the first time allowed for the examination of the relationship of the practices observed to evidence-based medicine as well as the exploration of the obstacles to following standardized guidelines. By publishing this research tool, the team aims to describe the process of its construction and critically examine its performance, so that others in the field of Safe Motherhood may benefit from our experience.

\section{Studv Objectives and Methods}

\section{Objectives}

The study aimed to document the practices of health providers attending normal deliveries in a large and influential teaching hospital in Cairo, Egypt. It also aimed to explore the delivery experiences of the women giving birth there and to explain observed provider practices. The research aimed to clarify the extent to which common provider practices are evidence-based, to explore barriers and obstacles to adopting protocols and to describe women's perceptions of their birthing experience.

Figure 1: Stages documented for each woman

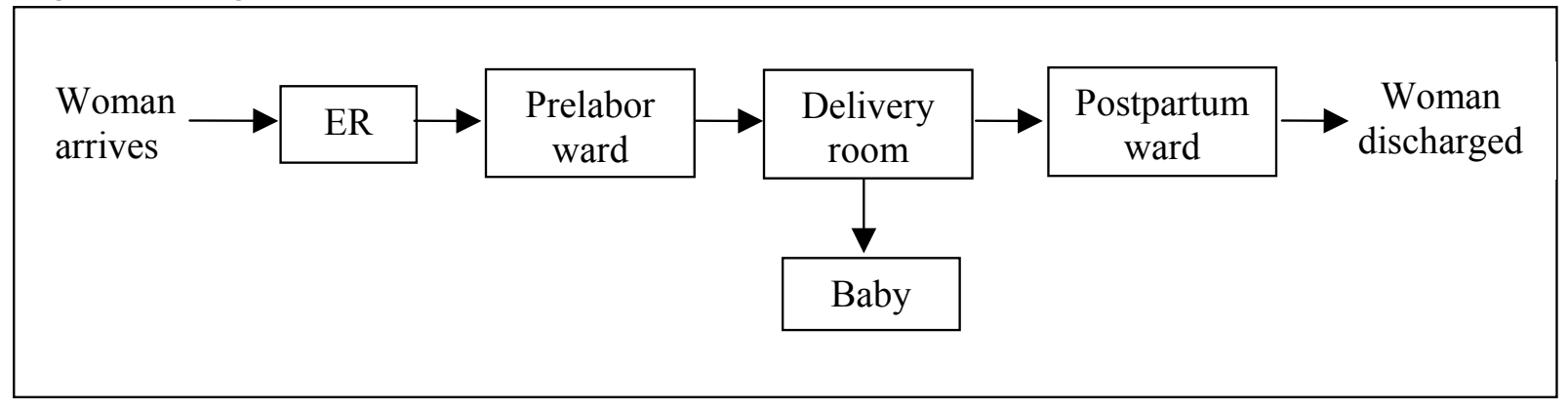




\section{Data collection methods}

A variety of qualitative and quantitative methods were used for data collection. To comprehensively record all provider practices involved in normal labor and delivery, the study recorded over 537 variables for each birth, using a checklist. Data was collected quantitatively and qualitatively by directly observing individual women for their entire labor and delivery (as shown in Figure 1); by documenting ward activities pre and postpartum, by interviewing the delivered women and discussing the findings with the providers.

\section{Comparison of findings with best-practice}

The practices observed were compared with best-practice based on a review of the available external clinical evidence. The 1999 World Health Organization Report of a Technical Committee on Practices for Normal Birth (WHO, 1999) was one of the clinical evidence sources consulted.

\section{Methodological choices}

Innovation in methodology and contribution to knowledge are the two main objectives of research. This is particularly true in Reproductive Health and Safe Motherhood where measuring the impact of obstetric interventions and accurately quantifying them is often problematic (Miller et al., 2003a). The first objective, developing methodology that is innovative, is arguably the harder of the two outcomes to achieve. To meet these two objectives; the research team made the following two methodological choices:

\section{Documentation of process vs. outcomes}

The documentation of practices rather than their clinical outcomes was deliberate and is intended as an alternative research direction to health research which focuses on outcome measures. When processes are supported by research-based evidence, their measurement provides valuable indicators of quality of care. Outcomes of faulty practices are well-documented in the literature. Our study therefore chose to record the hitherto undocumented frequency of the practices rather than their clinical consequences.

\section{Multidisciplinarity}

Of equal or perhaps greater importance, are the methodological contributions of the study. The multidisciplinary team that conceptualized and undertook the study structured a research project that intermingles the methods of medicine, public health, and social research. The objectives of the study, the design, the tools, and the analysis all reflect the conflation and complementarities of these as well as related fields. In this publication the team is providing the reader with the checklist used to structure the observations of women from the point of their admission to the point of their discharge from the hospital. This structured observation of the complete process of normal labor and delivery is rare in the literature. The first examination of facility practices for normal labor and delivery in the Arab World was carried out in Lebanon by interviewing 
providers (Khayat and Campbell, 2000). Observations of facility-based midwives have been conducted in Morocco (Leimel et al, 1999), and in Zambia (Maimbolwa et al, 1997). A selection of obstetric facility practices has been documented by direct observation in the Dominican Republic (Miller et al, 2003b). However, we were unable to locate a comprehensive documentation of facility-based obstetric practices for normal labor by direct observation, from the Arab region or elsewhere. By collecting data through direct observations of actual practices, the study team hoped to avoid biases inherent in interviews and record audits.

The study developed and used the checklist described here to document the actual practices of health providers involved in deliveries. The checklist is the primary data collection tool through which the study arrived at its findings. Other qualitative methods such as continuous observations of pre-labor and postpartum wards, individual interviews of patients and providers, and focus groups were also used in an effort to triangulate and understand the findings.

\section{The Research Process}

In this next section we would like to briefly outline the steps taken to reach the study findings. These steps began with an identification of a lack of knowledge concerning practices for normal delivery and ended with a rich body of findings. To get from there to here a team of four obstetricians, an anthropologist, a public health physician and a data manager went through the following processes:

\section{- Ethical review}

The proposal developed by the team outlining the study's objectives and methods was subjected to The Population Council's ethical review (IRB) process and to the WANA office Research Review Committee. The substantive review conducted by the Research Review Committee ensured that ethical as well as methodological issues relating to the research were addressed to the Council's satisfaction

\section{- Developing the checklist}

The lengthy process of compiling this checklist is worth sharing with the reader. First the team looked at existing observation tools with the idea of adapting the most relevant of such tools to the Galaa setting. To investigate this setting, a number of team members undertook some unstructured observations of the hospital wards and birthing rooms to acquire an on-the-ground understanding of the system, those who work in it and the patients whom it serves. These investigative ventures into the hospital quickly revealed that no amount of adaptation of existing tools could replace the benefits of designing an original tool. The checklist was laboriously put together over several months so as to capture all possible relevant aspects of birth as a holistic process, not only as a medical event, but also as a health, social and personal experience for both mother and baby. It was felt that the perceptions of the woman giving birth were as important as the technical aspects of the delivery. The process of capturing so much but 
maintaining the viability of the tool and the feasibility of the study was quite a challenge. 


\section{- Piloting the checklist}

The initial checklist that ensued from six months of deliberation was piloted at the facility in November 2000. Twelve days of observations by 5 observers in shifts yielded data on sixty-nine births. Findings from this pilot tool were fully analyzed. The main purpose of this analysis was to assess the quality of the checklist itself. The process of reviewing, revising and expanding the checklist in light of the pilot experience took one year, and involved three obstetricians, the medical anthropologist, the public health physician and the data manager equally. The postpartum section was lengthened and the logistics of data collection for this stage were changed. Sections on the emergency room and the neonatal care were designed and added and a neonatologist joined the team. In addition, the decision was taken to conduct all observations in both the paying and nonpaying sections of the hospital. All decisions regarding which items to include, their wording and sequencing were made by team consensus. The checklist included here (Appendix A) is the one that was ultimately used._It is broadly divided into 6 parts:

1. The Emergency Room

2. The Prelabor Ward

3. The Labor Ward

4. The Neonate

5. The Postpartum Ward

6. The interview with the delivered mother

The observation checklist includes 163 questions in English and 25 interview questions in Arabic.

\section{- Training and preparing for data collection}

In addition to the process of compiling the checklist, much effort was invested in testing the tool and training the observers. First 14 qualified female obstetricians who were not staff at the facility, were selected from a pool of interested researchers, to conduct the observations. These were trained, in a group, by the study team. The training involved familiarization with the study objectives, with the hospital setting, with the medical and social components of the tool and with the logistical processes of the data collection. This was followed by a pretest where the observers carried out data collection over three days and nights, in shifts, strictly according to the agreed-upon field methodology. This yielded data on 18 complete labors and deliveries.

After the pretest and debriefing of the observers four final steps remained before data collection could proceed. The first was to analyze the pre-test data using SPSS. At the same time, observers whose performance had proved inadequate or obtrusive were deselected. Twelve observers were retained. The third step was to do a final edit of the checklist, rearranging the sequencing and re-wording where necessary. The fourth was to revise the logistics of the data collection process. In retrospect, the pre-test proved extremely valuable in finalizing the checklist and ironing out logistical issues. 
Finally, 200 copies were made of the checklist. These were numbered and made available to the 12 observers who carried out around-the-clock observations according to a set timetable that divided the 24-hour day into three consecutive 8-hour shifts.

\section{- Data collection}

Data collection took place between October $10^{\text {th }}$ and November $6^{\text {th }}, 2001.188$ delivering mothers who met the study inclusion criteria (being in active labor, having cervical dilatation between $3-6 \mathrm{~cm}$ dilation and no obvious obstetrical or medical risk factors) were recruited at admittance in the emergency room. There were no refusals. Observations were continuous over 28 days and nights; the labors and deliveries of 176 women were documented in full. Observations were discontinued for 12 women who developed complications at some stage during their labor, with provider practices documented up to that point in time.

Each woman was followed throughout the process of her labor, delivery and postpartum through discharge. One observer at a time would follow the woman throughout the hospital experience. When an observer's shift ended, the next observer picked up the checklist at the point where the previous observer had stopped and continued observing the woman for the next eight hours, and so on, until the delivered mother was discharged form the hospital. As the data collection was ongoing, the completed checklists were collected daily and manually reviewed by the research team, so that any queries could be immediately checked and resolved with the individual observer and so that the researchers could monitor inter-observer reliability. Observers were also debriefed collectively in two plenary sessions. The data from the observation checklist were analyzed using SPSS. The interview data were coded and entered on SPSS where appropriate. The open-ended questions were transcribed manually and read as narratives.

Observation bias was minimized by several factors: the continuous 24-hour nature of the observations over 28 consecutive days and nights desensitized providers to observers' presence. The heavy patient load ensured fairly typical provider behavior, and the observers did not attract attention or interfere clinically.

\section{- Findings}

The findings were organized under 18 main issues:

1. Demographic variables

2. Caseload

3. Facility preparedness

4. Assessment

5. Management of the $1^{\text {st }}$ stage

6. Management of the $2^{\text {nd }}$ stage

7. Management of the $3^{\text {rd }}$ stage

8. Pain relief

9. Recording
10. Infection control

11. Communication

12. Continuous monitoring

13. Hospital policies from the woman's perspective

14. Supervision of doctors in training

15. Immediate postpartum care

16. Postpartum care

17. Neonatal care

18. Discharge procedures 
While general facility preparedness was acceptable, many observed practices were not in line with evidence-based best practice. These are discussed separately (Khalil et al, (In Press), Cherine et al, 2003, among others). A selection of findings are shown in Appendix $\mathrm{C}$ to illustrate the range of data collected.

\section{This Publication}

A number of publications, disseminations, and initiatives have resulted from the study. One of these is this document, presenting the checklist as it was used together with a critical commentary that may help others to use it (and make adaptations where necessary) with an understanding of its inherent merits and problems. To compile this commentary, the checklist was very carefully revised by the members of the study team as well as by the observers. This process categorized the checklist into groups of questions that presented different methodological challenges. The questions that worked speak for themselves; they constitute the majority of the checklist items and yielded the substance of the study. Consequently they are left without commentary here. The commentary on the other groups of questions is important for a number of reasons.

First, the comments display the importance of self-criticism and assessment. They operationalize the hindsight of the study team who have used and analyzed the checklist in a way that may be instructive to readers embarking on similar research efforts.

Secondly, they raise issues which are frequently faced by health researchers and to which there may be no conclusive or obvious solutions. Often in research problems faced rely on the discretion of the researcher to arrive at the most advantageous resolution. With this publication, the study team seeks to share their discretionary decisions with the reader.

Third, there are questions that were dictated by the unique characteristics of the facility. The study team points out such questions to distinguish those that are only relevant to this particular facility from those that are typical of in the labor and birthing process anywhere.

Fourthly, some questions are difficult to answer and complex to analyze. These questions merit discussion because they point to the array of skills and depth of commitment (in terms of time) requisite of observational studies that follow diverse actors and a multitude of actions.

We hope that by sharing this tool which yielded such a wealth of data, with transparency and critical insight, that we can make a contribution to methods and methodological issues in the field of safe motherhood.

Following is a critical discussion which begins with some general comments on the whole tool. This is followed by an examination of groups of questions grouped under various categories, listed below. The questions discussed are clearly marked on the tool (Appendix A) with an asterisk. Minor linguistic and typographical changes have been made to the original. These are marked in bold print. Appendix B matches the findings with their corresponding question number. Examples of findings are shown in Appendix C. 


\section{Categories of Comments}

\section{A. General comments:}

1. Why observe the doctor?

2. The pros and cons of documenting timing

3. Reliance on cervical dilatation as a measure of labor progress

4. Question sequencing

5. Evaluating the appropriateness of practices

6. Evidence-based medicine as a research paradigm

\section{B. Comments relating to specific questions (arranged by type of comment):}

1. Questions that cover important issues but are problematic because of observer subjectivity

2. Questions that require stringent training and standardization

3. Questions that need classification during the analysis stage

4. Questions where a question or an instruction could be added

5. Questions that would benefit from editing or reformatting

6. Questions that should be deleted for one of the following reasons:

a. Because the information can be obtained by other questions

b. Questions yielding non-essential information

c. Questions that may not capture what they are intended to capture

d. Questions that overburden the observer

7. Questions that were excluded because of the research setting

\section{A. General Comments}

\section{Why observe the doctor?}

Throughout the checklist the observer is asked to note down the practices, actions, and reactions of the doctor. The research team is aware that many of these procedures are often undertaken by nursing and midwifery staff. However there are three reasons which caused the team to specifically refer to 'the doctor' in the tool.

While in other settings many of the procedures associated with normal delivery may be undertaken by various members of the medical team, our pilot study and the observations undertaken prior to data collection showed that the case is not so in Egypt. Most, if not all, of the procedures which are perceived to be even remotely medical or technical, are the domain of the doctor. Another activity undertaken as part of the study observed the division of labor as practiced by the medical team in both the pre and postpartum ward. Findings from this qualitative observation confirmed that doctors, regardless of their rank, undertake most of these activities. 
Secondly, the study aimed to understand that doctors perceive as routine practice. To achieve this, the checklist was designed to document the procedures or medications the doctor ordered, irrespective of whether these procedures were carried out or the medications were actually given. By doing this, the study tried to gauge the extent to which certain activities and services were seen as routine by the doctor, or in other words, internalized. This objective is discrete from the attempt to document the services that the woman actually did receive.

Thirdly, the team felt that adding a question asking who did perform these services if the doctor did not, would have made the checklist impossibly long. Thus the team was careful in its analysis to comment on the doctor only and not to offer commentary on the activities or lack thereof of other members of the medical team.

\section{The pros and cons of documenting timing}

Timing is essential to safe and successful delivery. However to record the times of the beginning and ending of procedures, stages, and outcomes can be difficult. The checklist relies heavily on accurate timing and its recording. To assure the reliability of data the checklist has been designed to include a twenty-four hour clock which helped observers focus on the recording of accurate time. Moreover, timing was thoroughly covered in the training of observers to insure that they were highly sensitized to the importance of accuracy. All the timing questions in the checklist (Q1, 14, 15, 19, 20, 49, 51, 53, 56, 93, 123, 125, 129, 135, 140, 143b, 160,162 , table Q33 on P40, table Q37 on P46) yielded invaluable information that helped the research team assess the appropriateness of care given and the general management of each case. By looking at the timing of procedures relative to what was known of the woman's status at that point, the team was able to assess if the frequency of vaginal exams was appropriate, if the woman was neglected at any point in her delivery, when breastfeeding was initiated, and if the management of procedures and medications such as pain relief or oxytocin was according to acknowledged and prescribed guidelines and procedures or not.

The importance of timing has obvious implications such as making sure observers are wearing functioning watches. But it also implies that observers have to be well trained, and have the technical medical know-how to appreciate the importance of accurately recording the correct time.

\section{Reliance on cervical dilatation alone as a measure of labor progress}

The decision was taken to rely on cervical dilatation alone. Head station \& effacement (although included in the checklist) were usually not written down by the attending doctor. It would have been difficult for the observer to find out information regarding the woman's progress without asking the doctor. The checklist relied on cervical dilatation to keep asking the doctor to a minimum. If the checklist is used in a situation where effacement and head station data are easily retrievable from the woman's record, then they should be added. 


\section{Question sequencing}

It is important to remember that the sequence of questions in this checklist mirrors the sequence of normal labor and delivery procedures as they occur in the in the facility studied. However the reader is strongly advised to revise the sequence to reflect the sequential order of procedures in their own setting. The important thing to remember when thinking of sequencing is that questions should flow in an order that best facilitates capturing events and that also makes logical sense.

\section{Evaluating the appropriateness of practices}

Most of the checklist's questions yield direct yes and no answers that were recorded by the observers. The observers were not called upon to make judgments regarding the appropriateness of procedures they witnessed. This was the domain of the research team. Perhaps the most controversial, discretionary, and challenging aspects of this checklist are the groups of questions that construct criteria of appropriateness. These are the questions whose answers were grouped and reviewed by the team's obstetricians, and analyzed according to agreed-upon criteria so as to permit the medical experts to assess if together these answers reflect appropriate procedures or not. Issues that required answers to several questions to be assessed together to reach a decision regarding appropriateness are:

- Was the woman assessed promptly?

- Were the vaginal exams done when indicated?

- Appropriateness of the medications prescribed in terms of the labor progress (labor augmentation for example)

- Appropriateness of the fetal monitoring

- Availability of needed personnel at the right time

- Management of the third stage of labor

- Appropriateness of the newborn care

- Appropriateness of the newborn care for babies needing resuscitation.

- Appropriateness of the time of discharge

These appropriateness questions are the result of a methodological choice that needs commentary and explanation. The judgment of appropriateness was a great analytical burden placed on the shoulders of the medical members of the team. Each completed checklist was reviewed by the medical specialist who reached a judgment of appropriateness (or inappropriateness) of various practices by comparing data recorded in different sections of the checklist. This judgment was then added to the dataset, allowing a quantification of the prevalence of appropriateness for each practice in question. However the task of reviewing every checklist and matching the recorded measurements to set criteria needs both time and expertise. This design would not be possible with a very large sample or in the absence of medical experts willing to devote time to such labor-intensive analysis. 
The judgment of appropriateness does not really pose any challenges to the objectivity of the tool since the assessment of appropriateness was conducted according to criteria set by the whole team in consultation with various professional resources. It has therefore been a completely transparent process. In this spirit, all subjective adjectives such as "properly" and "adequately" were removed from the checklist. The only oversight which remains is Q67d, where "properly" should be removed.

\section{Evidence-based medicine as a research paradigm}

The World Health Organization Categorization of Practices for Normal Birth (WHO, 1999), which categorizes 59 common practices according to evidence of their benefit or harm, is a useful framework within which to present the study's findings. However, the checklist is not intended as a tool for measuring the extent to which the birth practices observed conform to this criterion alone. Firstly, the checklist documents 16 broad issues, yielding a variety of additional indicators and indices. Secondly, the study was entirely facility-based. Events that take place prior to admission or questions to which the answers were unknown because the equipment is not available, and that are part of the WHO categorization, were not included. Some questions need to be added if the tool is to be used to follow the WHO categorization. Examples of such questions would include:

- A question for observing if the provider performed massaging and stretching the perineum during the second stage of labor

- Maneuvers related to protecting the perineum and the management of the fetal head at the moment of birth

- Nipple stimulation to increase uterine contractions during the third stage of labor

- Routine use of oral ergometrine in the third stage of postpartum

- Bladder catheterization

\section{B. Comments on specific questions (arranged by type of comment)}

This section includes relatively simple categories such as deletion and rewording and the reasons for them as well as more complicated issues. Each group of questions is prefaced with an explanation of why these questions were problematic and how this was dealt with. Suggestions for alternatives or reasons why alternatives are hard to find are also given.

\section{Questions that cover important issues but are problematic because of observer subjectivity}

This includes questions that are open to subjective interpretation. For example the documentation of consent challenged the researchers. It is relatively easy to record if 
the provider asked for consent to conduct an examination. It is trickier to record the provision of consent by the patient. Perhaps she nodded her head, perhaps she was silent, or perhaps she went on to describe her symptoms as a way of giving implicit consent.

In Egypt the proverb says that "Silence is a sign of consent". Researchers cannot ignore these cultural dispositions. The study team felt it was unfair to insist on the verbalization of consent in a culture where so much is left unsaid. A concrete example may make the case.

In Q8 and Q26 the observer is asked to note whether before starting the vaginal examination in the ER, the doctor asked the woman for permission to examine her. Although seemingly simple, this was actually a difficult question to answer and proved even more difficult to interpret. There was the view that defining what constitutes permission is difficult in this situation and that permission is implicit, given that the woman has come to the ER. Some observers assumed this implicit consent. Others expected a verbalized request in the form of a question, for consent from the doctor before they could answer in the affirmative. Despite discussing 'what is consent?' in the training, the team felt uncomfortable with the data because of inter-observer variability in interpreting what permission is and the results of this question were discarded

The strong recommendation made here concerning inter-observer variability in these questions is to take into account varied interpretations during observer training, which is indeed what the research team tried to do. The training and pretest served to clarify and to some extent create codes for the interpretation of the meaning of the following questions. However in this critical commentary on the checklist, the team wishes to draw attention to the trickier aspects of these questions and to alert readers to the importance of standardization of their interpretation.

Another instance of inter-observer variability concerns the subjective interpretation of terms such as 'aggressive' in Q89. What are the tell-tale signs of aggression? Does aggression have to be displayed physically? If expressed verbally, should it be considered aggression? What about aggressive attitudes? The answers to these questions are highly subjective and threatened the integrity of the data in various ways. Observers may be unjust to providers by over-condemning them and considering silence or neglect as negative or aggressive attitudes. Or they may do an injustice to the women and consider only extreme displays of aggression as behavior worth noting thus ignoring a large grey area where providers may display aggression in discrete or subtle ways.

A possible alternative is to add the phrase 'in your opinion' to such questions and make it clear in the analysis and reporting that rates of aggression or support were measured according to the opinion of the observer. An added measure could be to debrief observers after the data collection and explain in narrative terms what they understood to be the meanings of such loaded terms. 


\section{Questions that require stringent training and standardization}

A category of questions the team would like to draw attention to concerns the standardization of technical definitions. Often we assume that we have a shared understanding of what technical terms mean. For example the team assumed that the meaning of "lubricant" in Q8 was obvious. This turned out to need clarification since some observers misinterpreted it and considered betadine, an antiseptic, a lubricant. This data could not be used. Another point where standardization is important concerns understanding the 'non-touch' technique in Q67, describing how sterile gloves are worn. These again are quite simple issues to address. They do however draw attention to the importance of a standardized and common understanding of every word in the checklist to assure the integrity and utility of the data.

\section{Questions that needed clarification during data analysis}

In order to document whether pain relief was offered, in table Q33 on P40-45, Q12b appears whenever a vaginal exam is done, as that is usually when the interaction occurs between the doctor and the laboring woman. In other settings it might be preferable to capture whether pain relief was offered at admission as well as repeatedly throughout the woman's hospital stay. It should also be remembered that in analyzing the response, the denominator here is not all vaginal exams done, but the number of women where this question was answered, as usually women in this setting are only offered pain relief once.

\section{Points where a question or an instruction could be added}

In this section there are some suggestions for additions to questions, parts of questions and instructions. We have listed the questions and the suggested alterations to them. Each suggestion would make the question more exact and easier to answer. As minor as they are the team still feels that the checklist would be better and easier to use if these changes were made. Many of the changes could only have come to light after the data was collected and analyzed. For example, we had no way of guessing that other patients may be the first to help the new mother initiate breast feeding until it was observed during the data collection. Hence we suggest the rewording and additions to Q149. Other suggestions are for the addition of clear instructions as in the table Q37 on P46. A third type of addition reflects the realization of a missed opportunity such as adding a question on ante-natal care to the post-partum interview.

An important point to make however is that the urge to add questions should be tempered by the care not to overburden observers or respondents. For this reason, in commenting on the checklist, the team has tended towards taking away items rather than adding more to the checklist. In the case of the post-partum interview for example, the team intentionally kept it as short and as precise as possible so that the tired mother is not oppressed by an avalanche of intrusive questions. The main guideline followed in the interview was to create an opportunity where mothers, so far silent and disengaged, could have their say about their recent and often painful, although ultimately happy experience. 
- In Q30, Q31 and Q32, (what items of the general examination were done) "was it recorded" should be added to each question for uniformity.

- "Who resuscitated the newborn?" Could be added after Q103.

- A question about immunization should be added to the checklist in the postpartum ward section, after Q147.

- Q112 ("Was there a tear to repair"), could be moved to follow Q74 and Q111 could be deleted.

- Regarding the vaginal exams (table Q33 on P40), adding space for findings such as effacement, station, position, can be done if they are obtainable from the woman's record, but not if this means eliciting the data by asking the provider repeated questions

- In the postpartum interview a question about whether the woman had followed antenatal care with a doctor or in a hospital should be added.

\section{Questions that would benefit from editing or reformatting}

This category of questions includes questions that would benefit from simple editing. The validity of these questions is not in doubt. The suggestions made here are with the aim of greater user-friendliness. Some need a change of words such as Q80, whether general anesthesia was "ordered" rather than "required" or Q116 where the word "tear" should replace "episiotomy", and others could benefit from reformatting. In both cases the information collected is unchanged.

Q138 regarding the woman's needs during labor is a good example of this category of questions. The original question was as follows:

- Q138. Did the lady need anything else during her stay in the post labor ward?

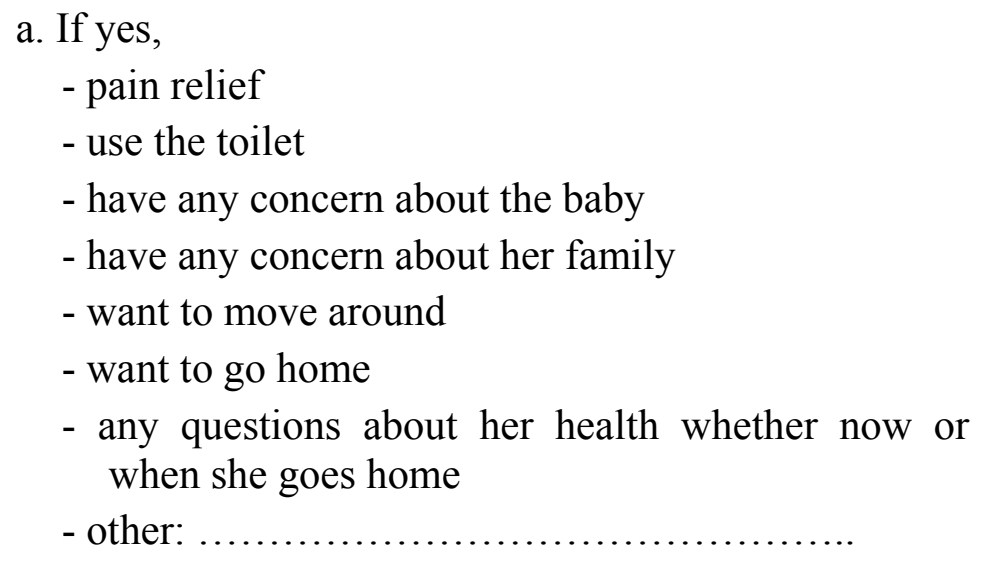

Team members tried to anticipate all the needs a woman could have but the denominator for each response was too small. Moreover the question does not ask who responded to these needs. One possibility would be to add a line under each 
option asking who responded. But researchers must keep the length of the observation sheet in mind when choosing to extend a question. Too many additions may make the observation sheet quite daunting and perhaps difficult to use.

Other questions that need reformatting are those that could not capture certain practices because of the use and misuse of certain labels or names. For example Q158 asks if the lady was given a discharge summary. The practice in the postpartum ward is to give women a variety of pieces of paper which are called discharge summaries but may in fact be something else. Women are often discharged with a prescription. The question should distinguish between a printed discharge summary or a prescription or another piece of paper. The difficulty here concerns the anticipation of variations that may elude even a pilot study or a pretest.

It is often with hindsight and the debriefing of data collectors that we realize how we can improve the data collection tool and make it more user-friendly. Q122 on whether the woman lay in the lithotomy position after the procedures were finished seemed a simple enough question. We only realized afterwards that the observers found it difficult to judge if all procedures were finished or not, and could not really determine if women were left in this position necessarily or un-necessarily. The data from this question were discarded.

Q95 and Q117 require more substantial re-wording:

- Q95. (How the third stage of labor was managed) should appear as:

During the second or third stages of labor, was an ecbolic given?

If yes,

a. Was it given:

- With the delivery of anterior shoulder

- After the delivery of anterior shoulder and up to 1 minute following delivery of the baby

- More than 1 minute after the delivery of the baby and before delivery of the placenta

- After the placenta

b.Type: .......

c. Dose: .......

d.Route: - direct IV as bolus or shot

- in the drip

- intramuscularly

- rectally

- vaginally 
- Q117. (Whether uterine exploration was done) should appear as

Was genital tract exploration performed after delivery?

If Yes,

a. How?

- Vaginal exploration (by finger)

- Cervical exploration (by instruments)

- Exploring uterine cavity (by introducing a hand in the vagina (manual))

b. Was this exploration:

- routine?

- because of a suspected problem?

c. Was anesthesia used?

d.If anesthesia was used, write the type:

Q92, Q140 and Q150-156 would be easier to use if reformatted as follows:

- Q92. (whether the woman asked for pain relief)

If yes, check every time she asked for pain relief whether:

- someone responded medically

- someone responded verbally

- Q140. (Items checked by the doctor in the postpartum examination). It would be easier for the observer to fill if it is formatted in an easy-to-use table such as the one shown:

General examination items checked postpartum

\begin{tabular}{|l|l|l|l|l|l|l|l|l|l|l|l|}
\hline Time & BP & Pulse & $\begin{array}{l}\text { Temp- } \\
\text { erature }\end{array}$ & $\begin{array}{l}\text { Fundal } \\
\text { height }\end{array}$ & $\begin{array}{l}\text { Uterine } \\
\text { tone }\end{array}$ & $\begin{array}{l}\text { Amount } \\
\text { of } \\
\text { vaginal } \\
\text { bleeding }\end{array}$ & $\begin{array}{l}\text { Perineal } \\
\text { repair if } \\
\text { present }\end{array}$ & $\begin{array}{l}\text { By } \\
\text { who }\end{array}$ & $\begin{array}{l}\text { Recorded } \\
\text { the } \\
\text { finding }\end{array}$ & $\begin{array}{l}\text { Noted } \\
\text { the } \\
\text { time }\end{array}$ & Signed \\
\hline & & & & & & & & & & & \\
\hline & & & & & & & & & & & \\
\hline
\end{tabular}

- Q150 - Q156. (Information given to the woman postpartum) These questions would benefit from the addition of two columns: one for "who gave the information" and one for "how they were given", instead of putting these at the end of the sequence. 
Such simple reformatting suggestions would make it easier for observers to complete the sheet and find an easy slot for their observations.

\section{Questions that can be deleted}

With hindsight the team recognized that the checklist could have been shorter. There are some questions that can be deleted but the reasons for this vary.

\section{a. Because the information can be obtained by other questions.}

No matter how careful researchers are in revising a tool repetitions are bound to occur. Some repetitions are useful because a question may not work and it is beneficial when you try to get the information in another way which does work. The list of questions that we consider repetitious is deemed so after all the data has been analyzed and with the security of knowing that the data has been derived from another question.

- $\mathrm{Q} 8,9,10,11,12$ and Q13. (Items relating to the vaginal exam in the ER). These are repeated in Table Q33 on P40 (information concerning all the other vaginal exams). It is more practical to have all the details concerning all the vaginal exams in one location, i.e. in table Q33.

- Q34. (Disposing of contaminated items and sharing information) These are covered in table Q33.

- Q134g. (Encouragement to breastfeed) This is covered in Q135b.

\section{b. Questions that yielded non-essential information.}

Again the team discovered that the information from these questions is not essential only with the hindsight and the benefits of data analysis. At the time of the tool design and the pretest these questions were thought to have the potential to yield important details but in fact they did not.

- Q28. (Who brings the instruments before examination)

- Q83. (Whether the instrument table was ready)

- Q94. (Whether milking of the umbilical cord was done)

- Table Q33 on P40 (Whether the woman was asked to empty her bladder)

- Q52a,b,c (Information given at transfer)

- Q113b. (Whether light was provided for the episiotomy)

- Q114. (The type of suture material was used for repair) 


\section{c. Questions that may not capture what they are intended to capture.}

These were questions that permit a wide margin of discretion and subjective interpretation on the part of the observers. Again, the team only recognized this margin of interpretation upon the analysis of data yielded by these questions. Although they are questions that attempt to gauge important information they are better deleted because of the difficulty of standardizing the responses. For example, do the words positive and negative mean the same thing for all observers in question Q49? Also, in some cases, information can be difficult for an observer to capture. When a doctor is reading a woman's file, it is difficult to know if he/she is checking the name or looking at other information in Q58.

Although these interpretations and definitions of concepts should be covered in the training of observers, the team realizes from experience that it is impossible to make sure that all words and their interpretations are commonly understood in a standardized way. The team therefore chose to discard the findings from these questions.

- Q49. Pain relief table: (How did they respond? Verbally in a positive way, verbally in a negative way)

- Q58. (Whether the delivering doctor checked the name of the lady with that of the file)

\section{d. Questions that overburden the observer}

With hindsight the research team appreciates the cost of each question in terms of the attention demanded from the observer and can carefully weigh the benefit or yield from the question. Despite their relevance and interest, some questions can be dropped because their yield does not justify the effort demanded from observers. For example Q36, asking if one of the staff explained to the lady that she would be examined by different providers, seems a straightforward yes or no question. In fact, it means that the observer must hear every exchange between any and all providers and the patient to know if she was told this or not at not. She should not ask the lady herself, who may be in too much pain or otherwise distracted, to be able to give a correct answer. The team feels that the answer does not justify the effort and recommends the deletion of the question.

\section{Questions that were excluded because of the research setting}

There are many questions not included in the observation checklist despite their relevance to normal labor and delivery. We did not ask about the use of partogram because we know they do not exist in the facility. We did not inquire if the doctor in the prelabor ward washed his hands because we know there is no sink. We also know that the prelabor, labor and postpartum wards are all within meters of each other so the means of moving patients from one to the next are not particularly difficult. Other initiatives should perhaps include these questions. The important issue is to design an instrument that does not waste precious resources to ask irrelevant questions. Establishing the relevance of each question requires close unstructured observation of the practices of health providers in specific facilities. 


\section{Conclusion}

The observation checklist yielded a very broad and rich dataset on normal labor and delivery practices in a major maternity hospital, which could not have been collected any other way. However, there is room for improvement, hence this commentary. Also, it is important to remember that the observation checklist was not the only tool of research in the birthing study. Qualitative tools provided the study with much of its contextual and vital information. The flow of patients and the variability of caseload, the division of responsibilities between various providers, women's perceptions, and the lack of standardized discharge procedures, are all dimensions of the study garnered from these qualitative approaches. These tools complemented each other at many levels and helped to enrich the study.

Publishing the observation checklist here does not negate the importance of these other methods. This first publication is meant to consider the observation checklist on its own terms, in a simple and direct manner, so as to provide an illustration for health researchers on the process by which observation tools are developed and used. It is our sincere hope that we succeed in this task. 


\section{References}

Akins S. 1994. Postpartum hemorrhage: a 90s approach to an age-old problem. Journal of Nurse-Midwifery. Volume 39, No. 2. Supplement: 123S-134S.

Cherine M, Hassanein N, Elnoury A, Sholkamy H, Mohsen L, Breebaart M and Khalil K. 2003. Observed normal labor practices and evidence-based medicine. Presented at the Fourth Annual Meeting of Gynecology and Obstetrics, Cairo University, March 2728, 2003. Cairo.

EDHS. 2001. Egypt Demographic Health Survey 2000 Final report. Cairo: Ministry of Health and Population, National Population Council. Calverton, Maryland: Macro International.

Egypt Ministry of Health and Population. 2001. National Maternal Mortality Survey: 1999-2000. Preliminary report: findings and conclusions. Cairo: Ministry of Health and Population.

Healthy Mother/Healthy Child. 2001. Memorandum of cooperation for the provision of technical assistance for the Healthy Mother/Healthy Child Results Package between USAID (including its contractor John Snow, Inc) and Ministry of Health and Population of ARE Maternal and Child Health Department.

Khalil K, Cherine M, Elnoury A, Sholkamy H, Breebaart M, Hassanein N. Labor augmentation in an Egyptian teaching hospital. International Journal of Gynecology and Obstetrics. (In Press)

Khayat R, Campbell O. 2000. Hospital practices in maternity wards in Lebanon. Health Policy and Planning, Volume 15, No. 3, pp.270-278.

Leimel A, Ncir L, Lachheb N. 1999. Medications used in the delivery room, SouissiRabat maternity facility. Rabat, Morocco: Institut de Formation aux Carrieres de Sante;[7],89,[7]p.

Maimbolwa MC, Ransjo-Arvidson AB, Ng'andu N, Sikazwe N, Diwan VK. 1997. Routine care of women experiencing normal deliveries in Zambian maternity wards: a pilot study. Midwifery, Volume 13, No. 3, pp.125-31.

Miller S, Sloan NL, Wnikoff B, Langer A, Fikree FF. 2003a. Where is the "E" in $\mathrm{MCH}$ ? The need for an evidence-based approach in safe motherhood. Journal of Midwifery \& Women's Health. Volume 48, No. 1, pp. 10-18. 
Miller S, Cordero M, Coleman AL, Figueroa J, Brito-Anderson S, Dabagh R, Calderon V, Caceres F, Fernandez AJ, Nunez M. 2003b. Quality of care in institutionalized deliveries: the paradox of the Dominican Republic. International Journal of Gynecology and Obstetrics, Volume 82, pp.89-103.

World Health Organization. 1999. Care in Normal Birth: a Practical Guide. WHO Report of a Technical Working Group. WHO/FRH/MSM/96.24. Geneva: WHO.

WHO. 2001. Global estimates of maternal mortality for 1995: results of an in-depth review analysis and estimation strategy [statement]. Geneva: WHO. 
APPENDIX A

THE OBSERVATION CHECKLIST 


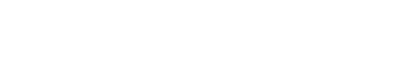

من فريق بمث تايع لمجلس للسكلن الدولي بيعطل درلسة عن مستوى أنا د. الخمة في المستثف هنا بالتعاون مع إدارة المستشفى. (I am Dr. from a team of researchers from the Population Council. We are studying the quality of care here in the hospital in collaboration with the hospital administration.)

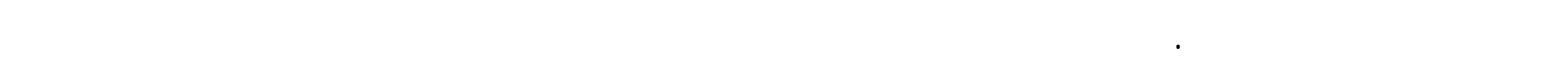

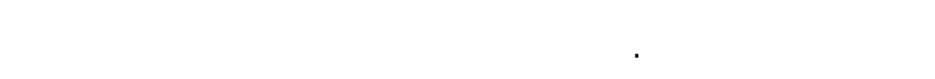

(I am a doctor but I do not work here. We are attending some deliveries from the beginning until the birth and would like to sit with you during this period. Would you allow us to sit with you and attend your delivery?)
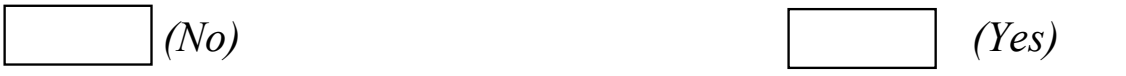

إمضاء البلحثة (Observer's signature) :

\section{A REMINDER OF THE 24-HOUR CLOCK}

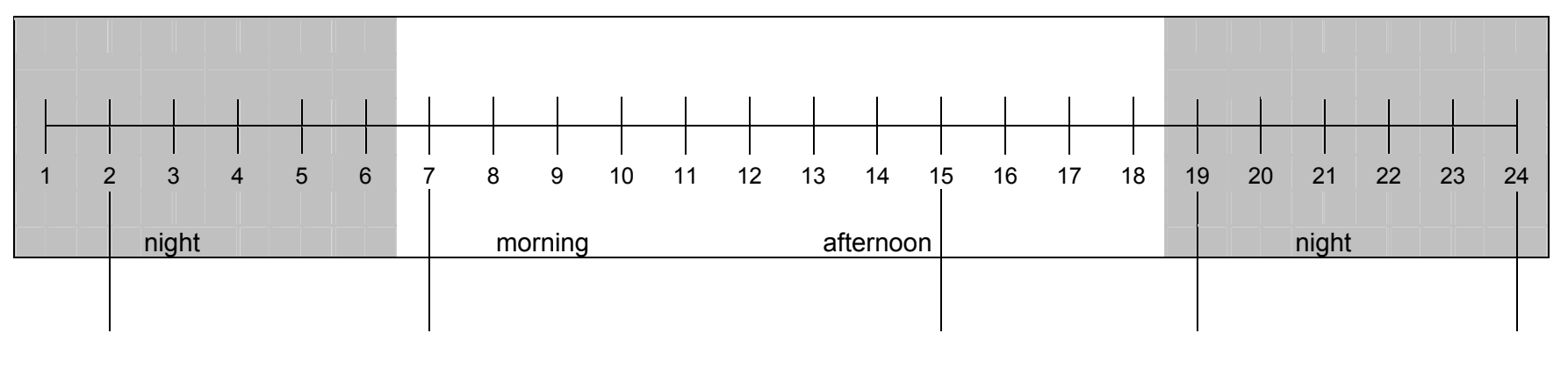


Serial \#

\title{
Study on Hospital Policies and Practices \\ Regarding Normal Labor in Egypt
}

\author{
Emergency Room Checklist
}

Department:

Observer's name:

Date of observation:

Beginning of observation:

End of observation:

Name of the patient:

Note: This part of the study will be conducted by means of observation and record audit of Ob/Gyn. physicians.

STOP OBSERVATION IF A COMPLICATION OCCURS AT ANY TIME

If observation had to stop because of a complication

1. At what time did the complication happen?

2. What is the lady's progress at this time?

3. What is the type of complication? 
EMERGENCY ROOM OBSERVATION

\begin{tabular}{|c|c|c|c|c|}
\hline \multirow{2}{*}{ 1- What was the time of the first exam in the E.R.?* } & Yes & No & NA & Code \\
\hline & & & & \\
\hline \multicolumn{5}{|l|}{ 2- Did a doctor take the history? } \\
\hline \multirow{2}{*}{\multicolumn{5}{|c|}{$\begin{array}{l}\text { History taking } \\
\text { 3- Is there a printed form to be followed? }\end{array}$}} \\
\hline & & & & \\
\hline \multicolumn{5}{|l|}{ a. if yes, was it followed? } \\
\hline \multirow{2}{*}{\multicolumn{5}{|c|}{$\begin{array}{l}\text { b. did a doctor ask about: } \\
\text { 1. the personal history }\end{array}$}} \\
\hline & & & & \\
\hline \multicolumn{5}{|l|}{ i. did a doctor record it? } \\
\hline \multicolumn{5}{|l|}{ 2. the present history } \\
\hline \multicolumn{5}{|l|}{ i. did a doctor record it? } \\
\hline \multicolumn{5}{|l|}{ 3. the obstetric history } \\
\hline \multicolumn{5}{|l|}{ i. did a doctor record it? } \\
\hline \multicolumn{5}{|l|}{ 4. the past medical history } \\
\hline \multicolumn{5}{|l|}{ i. did a doctor record it? } \\
\hline \multicolumn{5}{|l|}{ 5. the surgical history } \\
\hline \multicolumn{5}{|l|}{ i. did a doctor record it? } \\
\hline \multicolumn{5}{|l|}{ 6. the family history } \\
\hline \multicolumn{5}{|l|}{ i. did a doctor record it? } \\
\hline \multicolumn{5}{|l|}{ c. was it signed? } \\
\hline \multicolumn{5}{|l|}{ d. was the time recorded? } \\
\hline $\begin{array}{l}\text { 4- Before starting the examination, did a doctor explain what would be } \\
\text { done? }\end{array}$ & & & & \\
\hline
\end{tabular}


5- During the general examination, did a doctor:

a. check or ask assisting staff to check:

1. the BP

i. did a doctor record it?

2. the pulse

i. did a doctor record it?

3. the temperature

i. did a doctor record it?

b. auscultate the chest?

i. did a doctor record it?

c. auscultate the heart?

i. did a doctor record it?

d. check the legs?

i. did a doctor record it?

6- Did a doctor examine the abdomen?

i. did a doctor record it?

7- Did a doctor check the fetal heart sounds?

a. If yes, with

- Pinard

- Sonicaid

- CTG

b. did a doctor record it?

\section{Vaginal Examination}

8- Before starting the vaginal examination, did a doctor:*

a. take her permission for the vaginal exam?*

b. what did he say?

c. ask the lady to bend her knees?

d. use gloves:

- sterile

- disposable not from the packet

- disposable direct from the packet

e. use antiseptic solution to wipe perineum?

f. use lubricant gel for the vaginal exam?*

g. cover her with a sheet? 


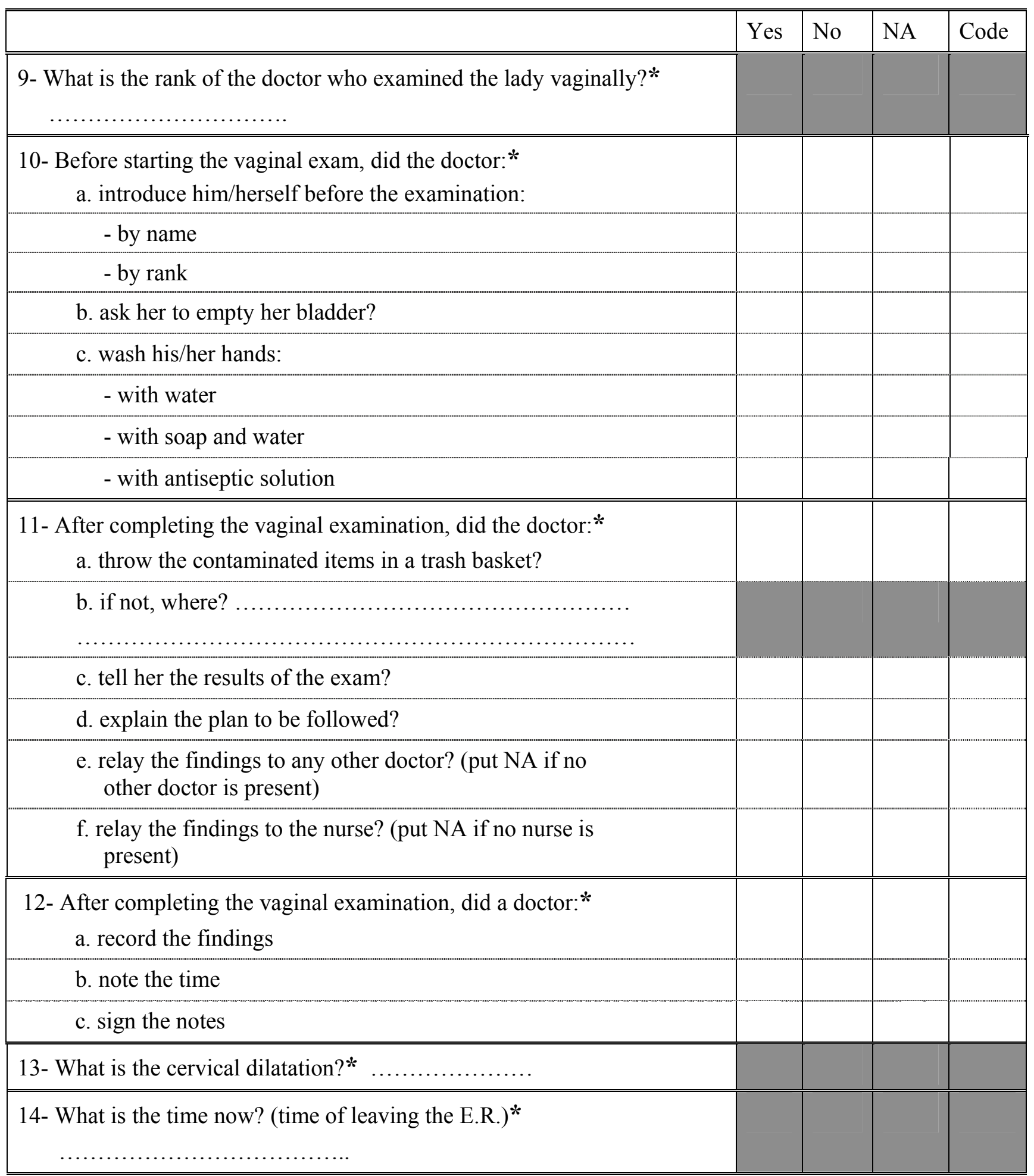


How many cases are in the waiting room once you've identified your case?

\begin{tabular}{|l|c|c|c|}
\hline Time & $\begin{array}{c}\text { No. of cases in the } \\
\text { waiting area }\end{array}$ & $\begin{array}{c}\text { No. of doctors in the } \\
\text { room }\end{array}$ & $\begin{array}{c}\text { No. of nurses in the } \\
\text { room }\end{array}$ \\
\hline & & & \\
\hline
\end{tabular}




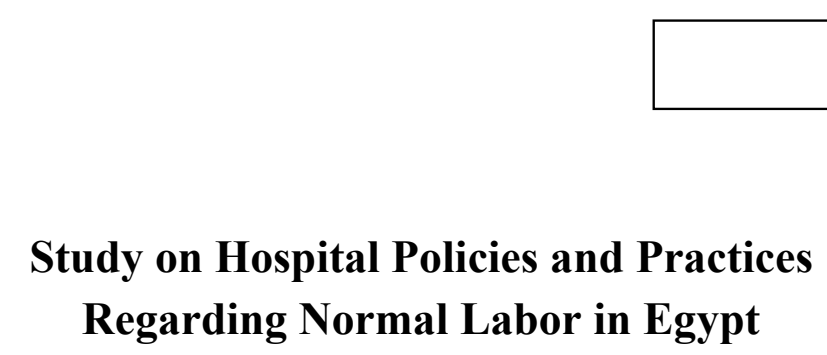

$\underline{1^{\text {st }} \text { Stage Observation Checklist }}$

Department:

Observer's name:

Date of observation:

Beginning of observation:

End of observation:

Name of the patient:

Age of patient:

Parity:

Patient number from file:

Note: This part of the study will be conducted by means of observation and record audit of Ob/Gyn physicians. 
OBSERVATION OF FIRST STAGE

\begin{tabular}{|c|c|c|c|c|}
\hline $\begin{array}{l}\text { Please remember how many different doctors examined the lady } \\
\text { vaginally so you can answer Q55 }\end{array}$ & Yes & No & NA & Code \\
\hline \multicolumn{5}{|l|}{ 15- Time of arrival of lady to the pre-labor ward:* } \\
\hline 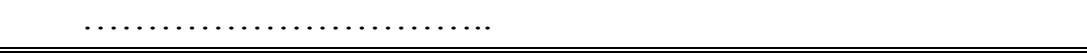 & & & & \\
\hline \multicolumn{5}{|l|}{$\begin{array}{l}\text { 16- Upon arrival to the pre-natal ward, } \\
\text { a. who met the lady? }\end{array}$} \\
\hline , & & & & \\
\hline \multicolumn{5}{|l|}{ b. was she told which bed/ room to go to? } \\
\hline \multicolumn{5}{|l|}{ 17- Who helped the lady to settle in: } \\
\hline \multicolumn{5}{|l|}{ - No one } \\
\hline \multicolumn{5}{|l|}{ - the house officer } \\
\hline \multicolumn{5}{|l|}{ - the nurse } \\
\hline \multicolumn{5}{|l|}{ - the worker } \\
\hline \multicolumn{5}{|l|}{ - other $\ldots \ldots \ldots \ldots \ldots \ldots \ldots \ldots \ldots \ldots \ldots$} \\
\hline $\begin{array}{l}\text { 18- Did a doctor review the admission data before doing the first } \\
\text { examination? }\end{array}$ & & & & \\
\hline
\end{tabular}

19- Time of reviewing the admission data:*

20- Time of $1^{\text {st }}$ examination by a doctor:*

\section{This question is not to be filled by the observer}

21- $a$. Was the time interval between arrival \& $1^{\text {st }}$ examination appropriate?

b. And the time before review of admission data?

22- Was the first person who examined the lady:

- a resident

- a house officer

- an assistant specialist

- a nurse

23- Did the doctor introduce him/herself before the examination:

- by name

- by rank

24- Did the doctor call the lady by her name? 


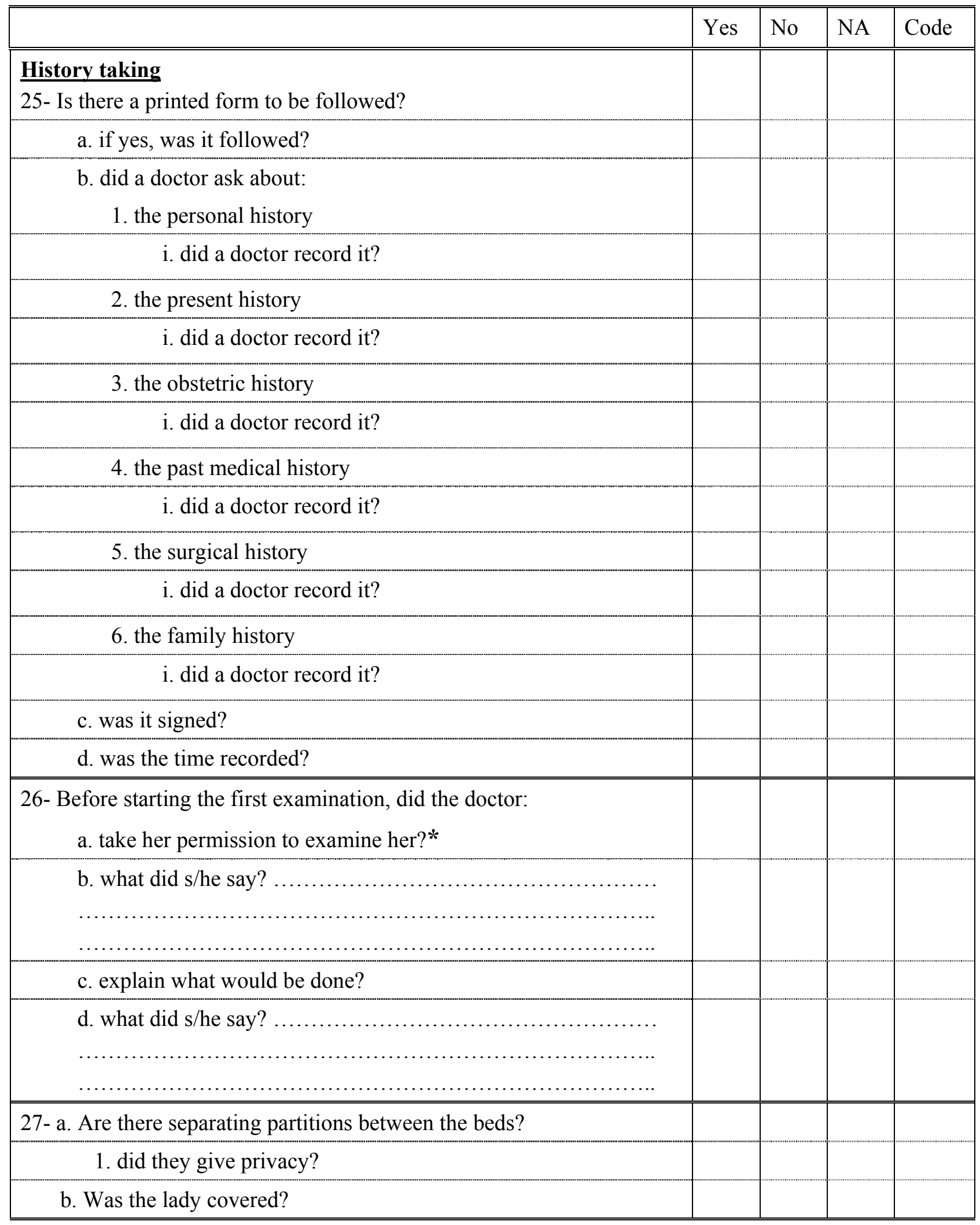




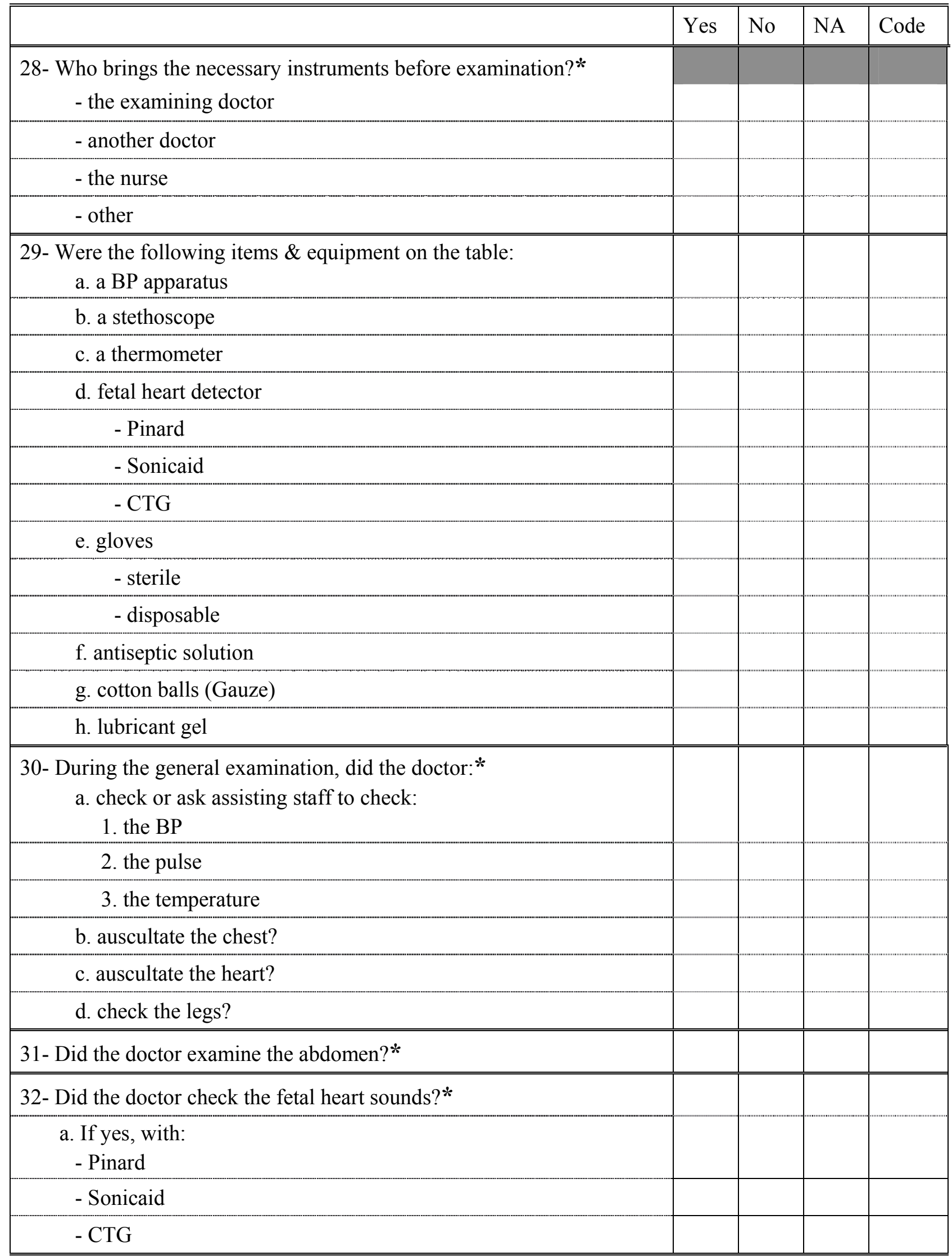

MARK THE VAGINAL EXAM DETAILS IN THE TABLE \#33 AT THE END OF THE CHECKLIST ON P40 


\begin{tabular}{|c|c|c|c|c|}
\hline & Yes & No & NA & Code \\
\hline \multicolumn{5}{|l|}{$\begin{array}{l}\text { 34- After completing the vaginal examination, did a doctor:* } \\
\text { a. throw the contaminated items in a trash basket? }\end{array}$} \\
\hline \multicolumn{5}{|l|}{ 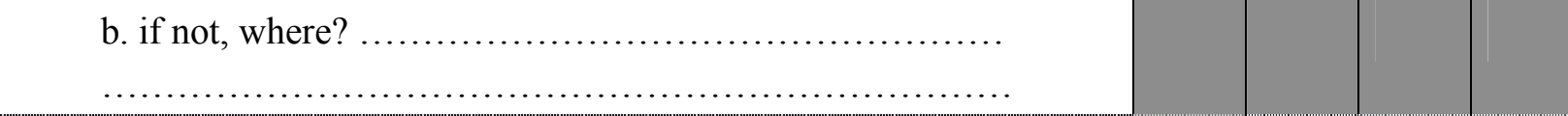 } \\
\hline \multicolumn{5}{|l|}{ c. tell the findings to the lady? } \\
\hline \multicolumn{5}{|l|}{ d. explain the plan to be followed? } \\
\hline \multicolumn{5}{|l|}{ e. relay the findings to any other doctor? } \\
\hline \multicolumn{5}{|l|}{ 35- Did a doctor ask for: } \\
\hline \multicolumn{5}{|l|}{ a. an enema } \\
\hline \multicolumn{5}{|l|}{ b. perineal shaving } \\
\hline $\begin{array}{l}\text { 36- Did one of the staff explain to the lady that she might be } \\
\text { examined by different providers?* }\end{array}$ & & & & \\
\hline
\end{tabular}

WRITE ALL MEDICATIONS AND FLUIDS ORDERED DURING THIS ENTIRE STAGE IN THE TABLE \# 37 AT THE BACK $($ P46, 47) AS WELL AS OTHER ITEMS IN THE TABLE 


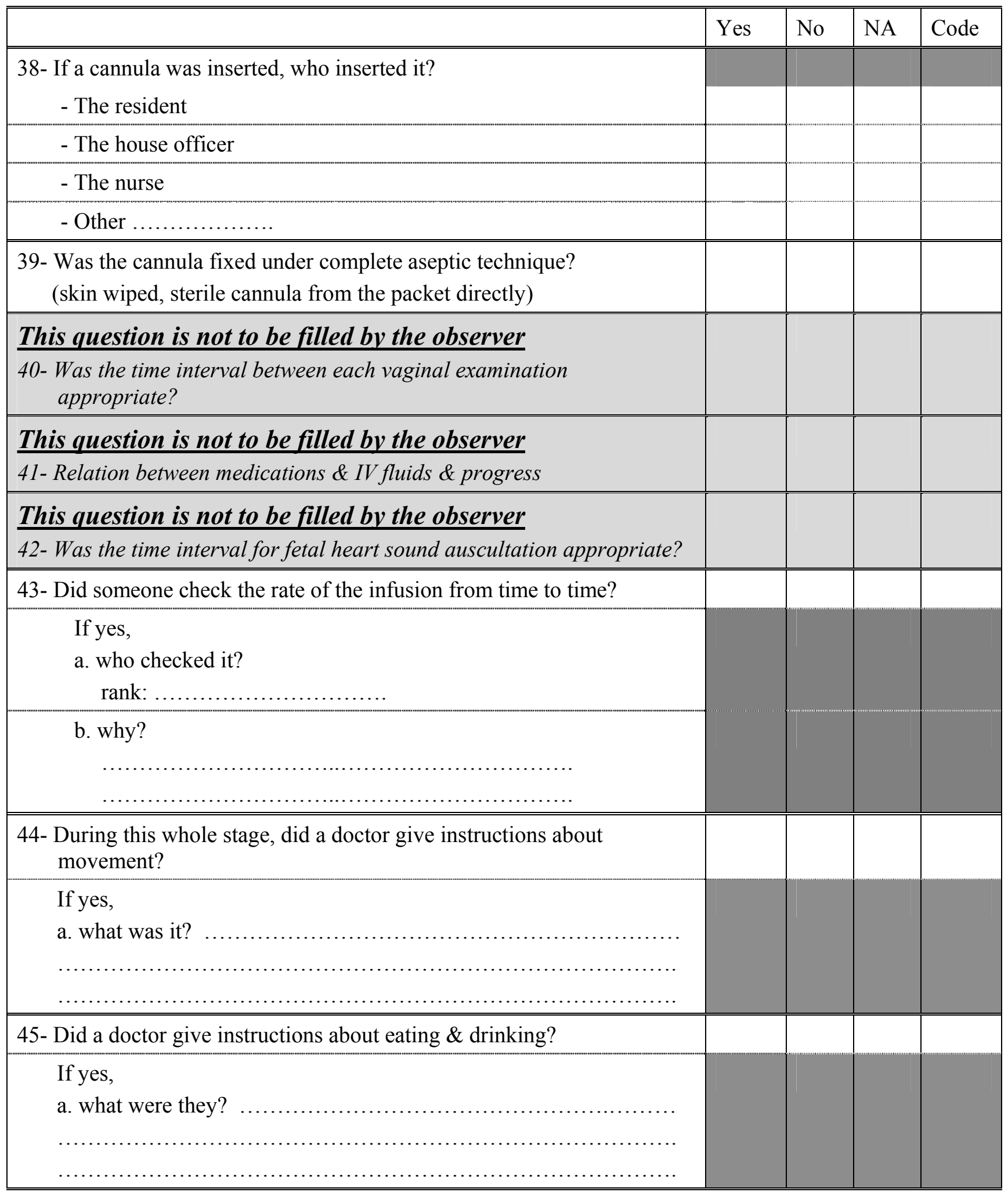




\begin{tabular}{|c|c|c|c|c|}
\hline & Yes & No & NA & Code \\
\hline \multicolumn{5}{|l|}{ 46- Did the lady request a doctor's permission to move about? } \\
\hline \multicolumn{5}{|l|}{$\begin{array}{l}\text { if yes, } \\
\text { a. was she allowed to move? }\end{array}$} \\
\hline \multicolumn{5}{|l|}{ b. if she was not allowed to move, ask a doctor why (if possible)? } \\
\hline \multicolumn{5}{|l|}{ 47- Did the lady want to eat? } \\
\hline \multicolumn{5}{|l|}{$\begin{array}{l}\text { if yes, } \\
\text { a. was she allowed to eat? }\end{array}$} \\
\hline \multicolumn{5}{|l|}{ b. if she was not allowed to eat, ask a doctor why (if possible)? } \\
\hline \multicolumn{5}{|l|}{ 48- Did the lady want to drink? } \\
\hline \multicolumn{5}{|l|}{$\begin{array}{l}\text { if yes, } \\
\text { a. was she allowed to drink? }\end{array}$} \\
\hline b. if she was not allowed to drink, ask a doctor why (if possible)? & & & & \\
\hline (1) & & & & \\
\hline
\end{tabular}


49. Pain relief*

SHADE THE BOX IF THE ANSWER IS "YES"

A. 1.Did the lady ask for pain relief?

2. Time*:

3. Did someone respond?

4. Who? Nurse $\square$

Doctor

Other $\square$

5. How did they respond?*

Verbally in a positive way

verbally in a negative way

With medication

6. Type of medication?

(write also in table \# 37 on P46)

7. Did this alleviate her pain?

B. 1.Did the lady ask again for pain relief?

2. Time*:

3. Did someone respond?

Doctor

Other

5. How did they respond?*

Verbally in a positive way

verbally in a negative way

With medication

6. Type of medication?

(write also in table \# 37 on P46)

7. Did this alleviate her pain?

C 1.Did the lady ask again for pain relief?

2. Time*:

3. Did someone respond?

4. Who? $\quad$ Nurse $\square \quad$ Doctor $\square \quad$ Other

5. How did they respond?*

Verbally in a positive way

verbally in a negative way

With medication

6. Type of medication?

(write also in table \# 37 on P46)

7. Did this alleviate her pain? 


\begin{tabular}{|c|c|c|c|c|}
\hline \multirow{2}{*}{\begin{tabular}{|l} 
50- Did the lady ask for anything? \\
\end{tabular}} & Yes & No & NA & Code \\
\hline & & & & \\
\hline $\begin{array}{l}\text { If yes, } \\
\text { a. what did she ask for? (in her own words) }\end{array}$ & & & & \\
\hline b. did someone respond? & & & & \\
\hline c. who responded? & & & & \\
\hline 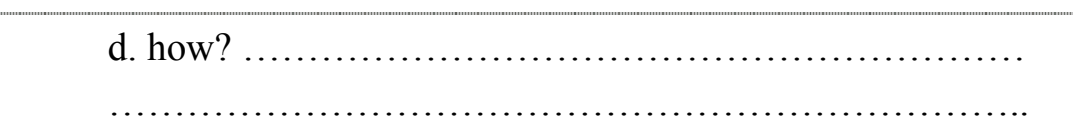 & & & & \\
\hline e. how long after the request? & & & & \\
\hline $\begin{array}{l}\text { 51- At what time did a doctor order the lady to be transferred to the } \\
\text { delivery room?* }\end{array}$ & & & & \\
\hline $\begin{array}{l}\text { 52- When the lady was ready to be transferred to the delivery room, } \\
\text { did a doctor:* } \\
\text { a. notify the lady about the progress? }\end{array}$ & & & & \\
\hline b. notify the lady what would be done for her? & & & & \\
\hline c. instruct the lady what to do? & & & & \\
\hline $\begin{array}{l}\text { 53- At what time was the lady actually moved from the prelabor } \\
\text { ward?* }\end{array}$ & & & & \\
\hline $\begin{array}{l}\text { This question is not to be filled by the observer } \\
54-\text { What is the interval between the last exam \& the transfer to the } \\
\text { delivery room? }\end{array}$ & & & & \\
\hline $\begin{array}{l}\text { 55- How many different doctors (or other staff) examined the lady } \\
\text { vaginally in the prelabor stage? }\end{array}$ & & & & \\
\hline
\end{tabular}


Comments

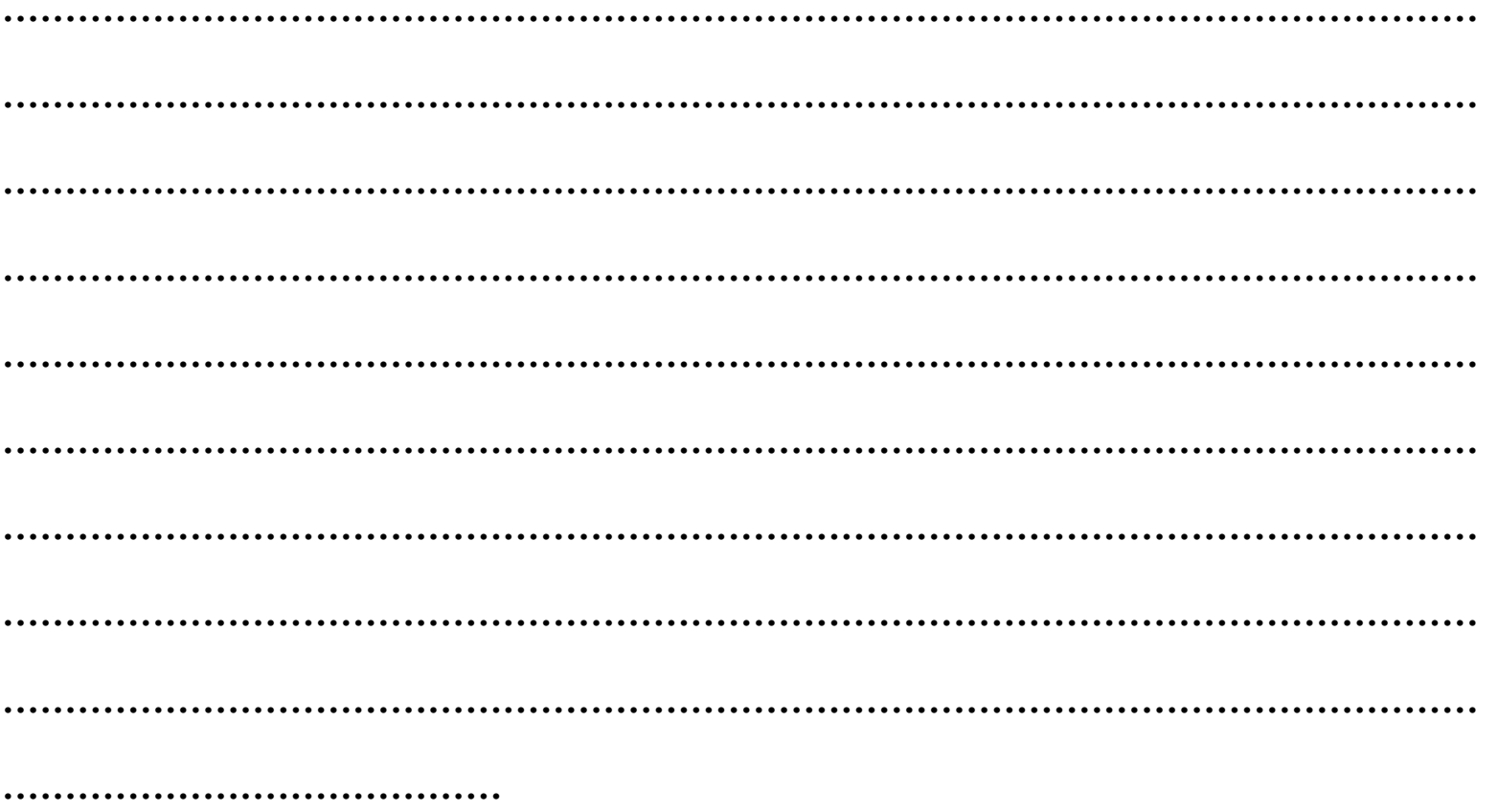




\section{Study on Hospital Policies and Practices \\ Regarding Normal Delivery in Egypt}

\section{$\underline{\text { Labor Observation Checklist }}$}

Department:

Observer's name:

Date of observation:

Beginning of observation:

End of observation:

Name of the patient:

Patient's number from file:

This part of the study will be conducted by means of observation and record audit of Ob/Gyn physician in the Delivery room. 
OBSERVATION OF LABOR

\begin{tabular}{|l|l|l|l|l|}
\hline & Yes & No & NA & Code \\
\hline
\end{tabular}

56- What time did the lady arrive in the delivery room?*

57- Was the lady covered while she was being moved from the pre-labor ward to the delivery room?

58- Did the delivering doctor check the name of the lady with that of the file?*

59- Did the delivering doctor check the findings in the file?

60- Was the delivering doctor one of the doctors who had seen the lady in the pre-labor ward?

a. If no, did s/he introduce him/herself by:

- name

- rank

- other:

61- Did the doctor who was there to deliver the lady explain what would be done?

62- What position did the lady deliver in:

- lithotomy

- squatting

- left lateral

- other

63- a. Were the lady's legs tied?

b. Were the lady's arms tied?

c. How were they tied?

64- Was the lady covered except for perineal area during the delivery?

65- Were partitions closed?

66- Before conducting the delivery, did a doctor wash his or her hands?

a. If yes,

- with soap and water?

- with only water?

- with antiseptic solution

- other: 


\begin{tabular}{|c|c|c|c|c|}
\hline & Yes & No & NA & Code \\
\hline \multicolumn{5}{|l|}{ 67- While delivering the lady, did a doctor wear gloves? } \\
\hline \multicolumn{5}{|l|}{$\begin{array}{l}\text { a. If yes, } \\
\text { - sterile }\end{array}$} \\
\hline \multicolumn{5}{|l|}{ i. using the non-touch technique* } \\
\hline \multicolumn{5}{|l|}{ - disposable } \\
\hline \multicolumn{5}{|l|}{ b. If gloves were not used, give a reason why: } \\
\hline \multicolumn{5}{|l|}{$\begin{array}{l}\text { c. Did the delivering doctor scrub the area with } \\
\text { antiseptic solution? }\end{array}$} \\
\hline \multicolumn{5}{|l|}{$\begin{array}{l}\text { d. Did the delivering doctor use sterile towels to } \\
\text { properly cover the lady?* }\end{array}$} \\
\hline \multicolumn{5}{|l|}{ 68- Did the delivering doctor ask the lady to push down? } \\
\hline \multicolumn{5}{|l|}{ 69- Did anyone explain to the lady when and how to push? } \\
\hline \multicolumn{5}{|l|}{$\begin{array}{l}\text { a. Who? } \\
\text { - the delivering doctor }\end{array}$} \\
\hline \multicolumn{5}{|l|}{ - the nurse } \\
\hline \multicolumn{5}{|l|}{ 70- Was fundal pressure applied? } \\
\hline \multicolumn{5}{|l|}{$\begin{array}{l}\text { a. If yes, who asked for it: } \\
\text { - the delivering doctor? }\end{array}$} \\
\hline \multicolumn{5}{|l|}{ - the nurse? } \\
\hline \multicolumn{5}{|l|}{ - other? } \\
\hline \multicolumn{5}{|l|}{ 71- Were any of the following instruments used: } \\
\hline \multicolumn{5}{|l|}{ - vacuum (ventouse) } \\
\hline \multicolumn{5}{|l|}{ - forceps } \\
\hline \multicolumn{5}{|l|}{$\begin{array}{l}\text { If yes, } \\
\quad \text { a. time of its use: } \ldots \ldots \ldots \ldots \ldots \ldots \ldots \ldots \ldots \ldots \ldots\end{array}$} \\
\hline \multicolumn{4}{|l|}{ b. reason for its use: } & \\
\hline \multicolumn{5}{|l|}{ - prolonged $2^{\text {nd }}$ stage } \\
\hline \multicolumn{5}{|l|}{ - routine } \\
\hline \multicolumn{5}{|l|}{ - other: $\ldots \ldots \ldots \ldots \ldots \ldots$} \\
\hline \multicolumn{5}{|l|}{ c. who used it? (rank) .............................. } \\
\hline d. rank of supervising staff: ........... & & & & \\
\hline
\end{tabular}




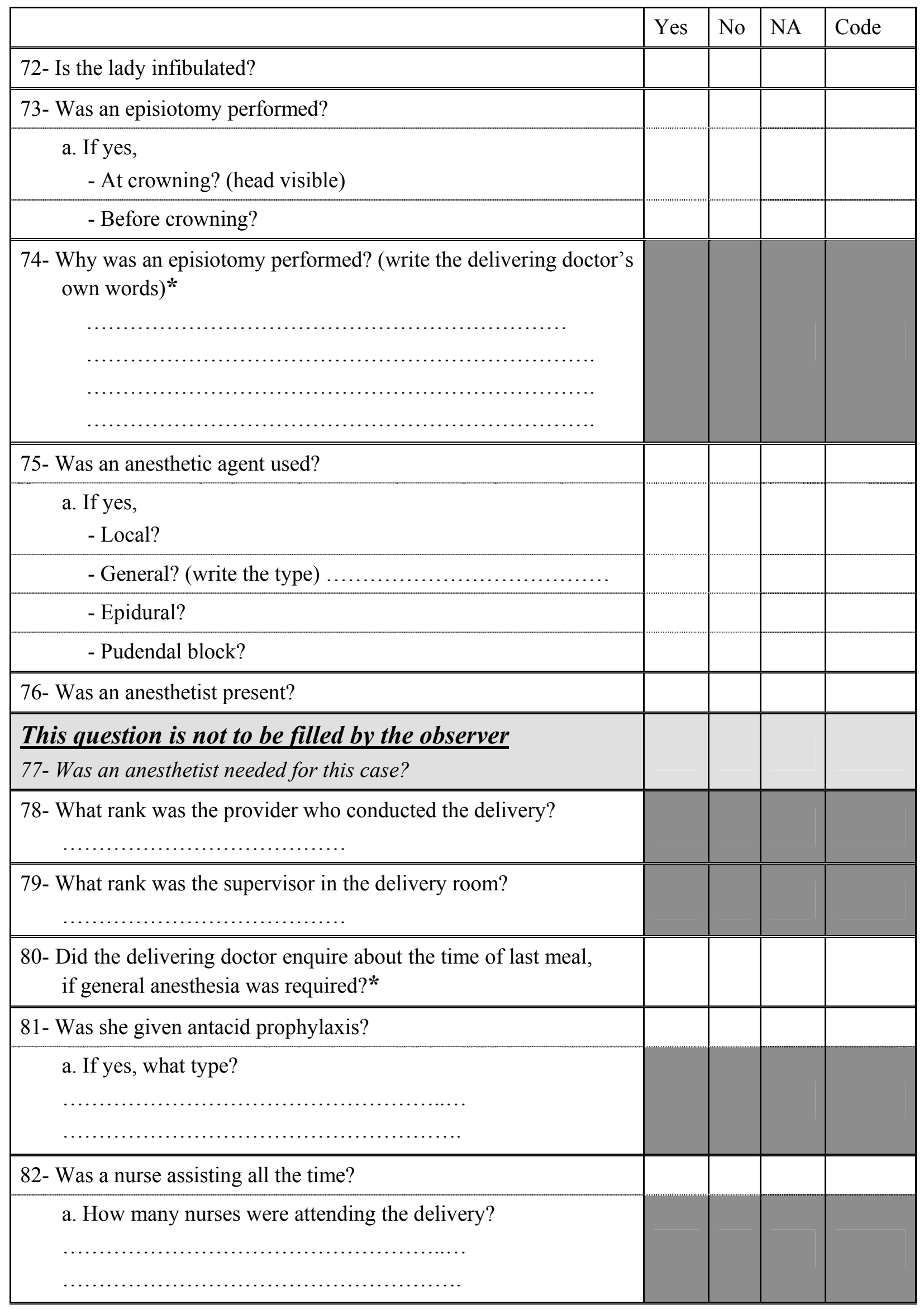




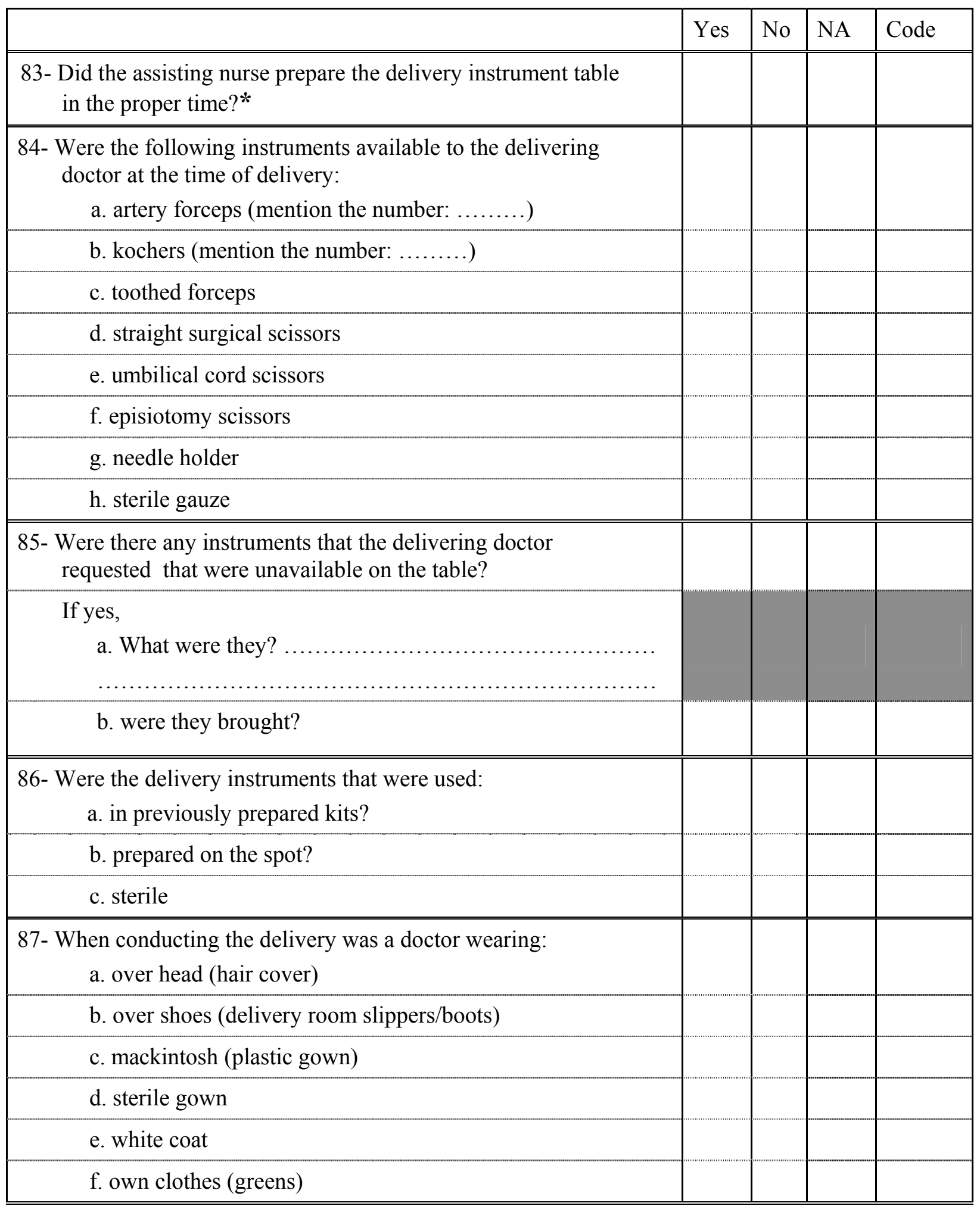




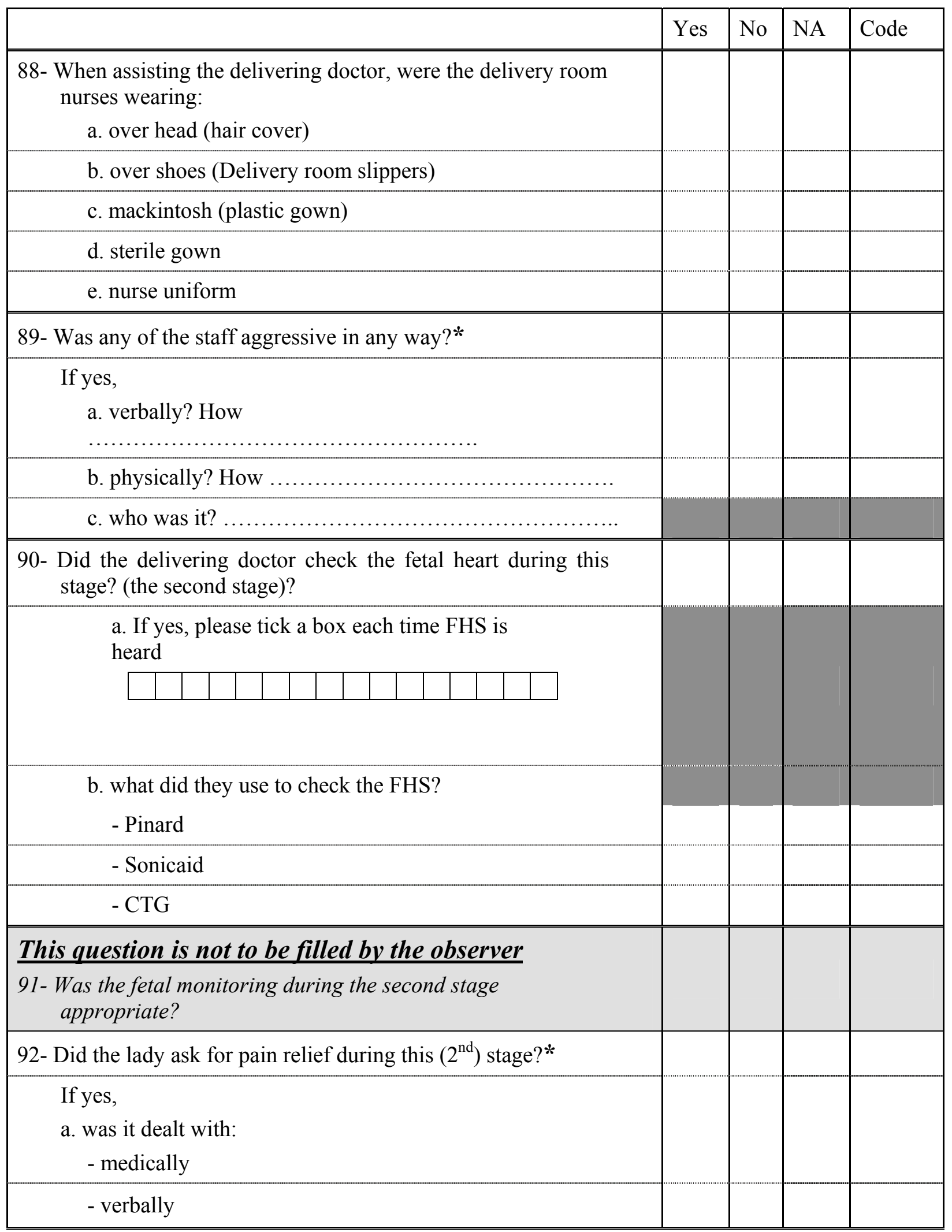




\begin{tabular}{|c|c|c|c|c|}
\hline & Yes & No & NA & Code \\
\hline 93- What is the time now (as soon as the baby is delivered)?* & & & & \\
\hline $\begin{array}{l}\text { 94- After the delivery of the baby was the cord:* } \\
\text { a. immediately clamped? }\end{array}$ & & & & \\
\hline b. was milking done? & & & & \\
\hline c. was there controlled cord contraction? & & & & \\
\hline $\begin{array}{l}\text { 95- During the second stage of labor, if was a bolus of oxytocit } \\
\text { given?* }\end{array}$ & & & & \\
\hline $\begin{array}{l}\text { If yes } \\
\text { a. was it given: } \\
\text { - before the delivery of the shoulder }\end{array}$ & & & & \\
\hline - after the delivery of the baby & & & & \\
\hline b. mention the type: .................................. & & & & \\
\hline c. mention the dose: ................................ & & & & \\
\hline d. mention the route: $\ldots \ldots \ldots \ldots \ldots \ldots \ldots \ldots \ldots \ldots \ldots \ldots \ldots$ & & & & \\
\hline
\end{tabular}

Questions 96 to 107 concern the management of the neonate. A second observer should be present to fill in this section.

The first observer, observing the delivered woman should proceed to question 108 .

In the study, Q96-107 were stapled separately, to allow for the simultaneous data collection for both the mother and the neonate by two observers. 
Serial \#

\section{Care of the Newborn}

Department:

Observer's name:

Date of observation:

Time of observation:

Name of the patient:

Patient's number from file: 
CARE OF THE NEW BORN

96- Once the baby was delivered who was there to receive him:

- a pediatrician

- an anesthetist

- a nurse

- a worker

- other

97- Was the baby placed on:

- a radiant warmer

- table

- taken to neonatal ward immediately

98- Was the following equipment available in a working order at the time of delivery:

a. a radiant warmer

b. an ambu bag

c. neonatal masks

d. an oxygen source

e. nasogastric tube for suction

i. was it opened for this baby?

ii. previously used?

f. a laryngoscope with straight blade

g. endotracheal tubes

h. an umbilical catheter

i. medications: epinephrine \& sodium bicarbonate

j. pediatric stethoscope

99- Was the baby?

a. dried

b. placed on his back with his head slightly extended

c. suctioned by a manual or electric suction

d. was the baby weighed?

100- When suction was done:

a. was the mouth suctioned first?

b. was the nose suctioned first?

c. did suction exceed 5 seconds? 


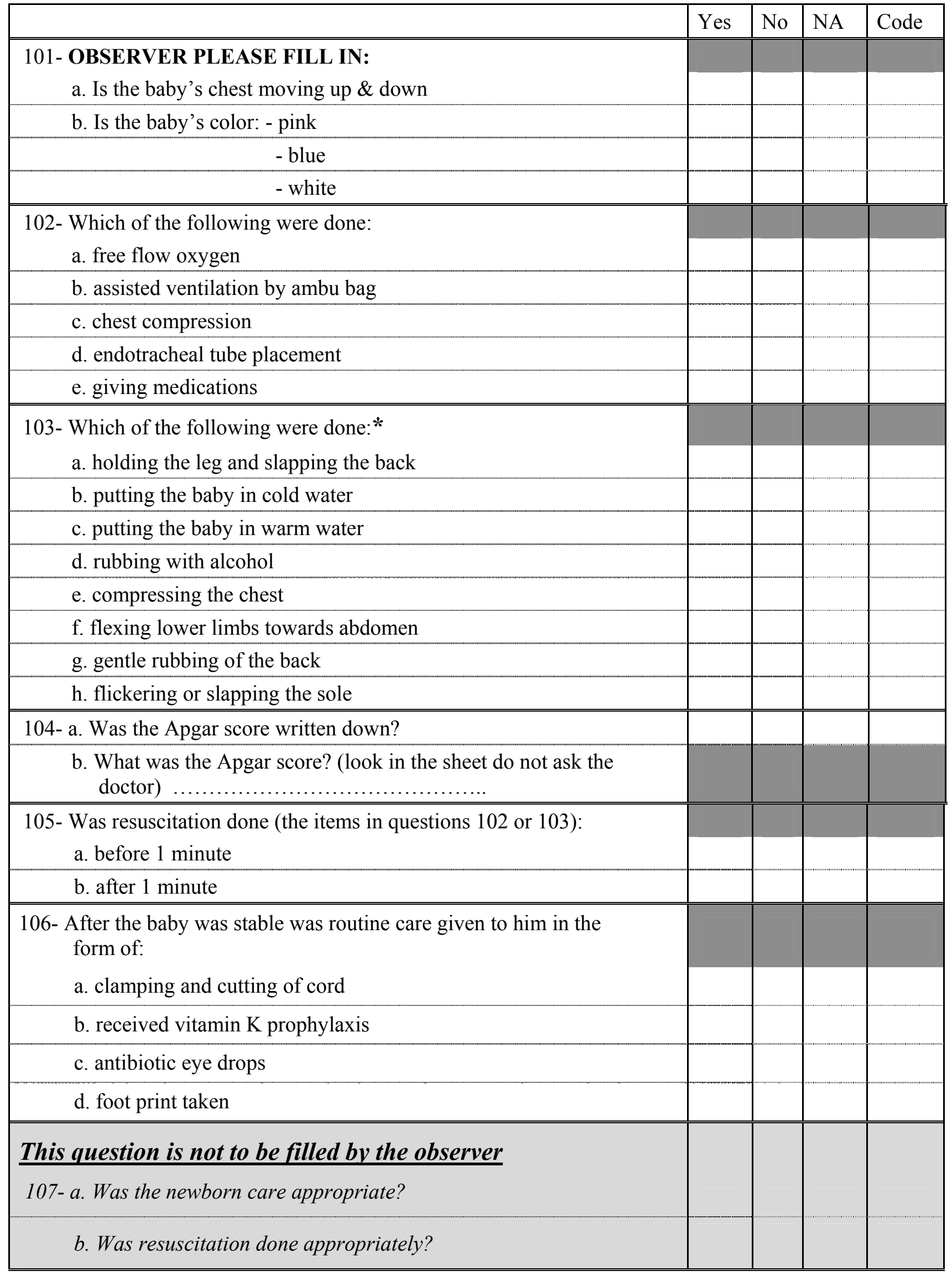




\begin{tabular}{|c|c|c|c|c|}
\hline & Yes & No & NA & Code \\
\hline \multirow{2}{*}{\multicolumn{5}{|c|}{$\begin{array}{l}\text { This question is not to be filled by the observer } \\
\text { 108- During the third stage of labor, did the delivering doctor follow } \\
\text { the active management approach? }\end{array}$}} \\
\hline & & & & \\
\hline \multicolumn{5}{|l|}{ 109- After delivery of the placenta, was it examined? } \\
\hline \multicolumn{5}{|l|}{$\begin{array}{l}\text { a. if yes, by: } \\
\text { - the delivering doctor }\end{array}$} \\
\hline \multicolumn{5}{|l|}{ - the nurse } \\
\hline \multicolumn{5}{|l|}{$\begin{array}{l}\text { 110- After delivery of the placenta, did the delivering doctor confirm } \\
\text { uterine contractility? }\end{array}$} \\
\hline \multicolumn{5}{|l|}{ 111- Was there an episiotomy to repair?* } \\
\hline \multicolumn{5}{|l|}{ 112- Was there a tear to repair?* } \\
\hline \multicolumn{5}{|l|}{$\begin{array}{l}\text { 113- If there was an episiotomy/tear to repair: } \\
\text { a. Was the lady informed about the procedure? }\end{array}$} \\
\hline \multicolumn{5}{|l|}{ b. Was adequate light provided?* } \\
\hline \multicolumn{5}{|l|}{ 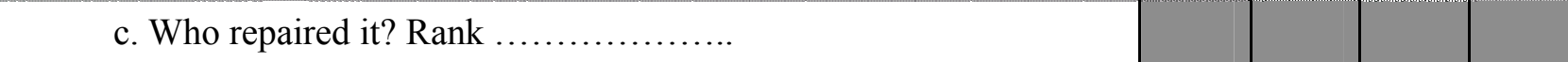 } \\
\hline \multicolumn{5}{|l|}{ d. Under whose supervision? Rank } \\
\hline \multicolumn{5}{|l|}{$\begin{array}{l}\text { 114- What type of suture material was used for repair?* } \\
\text { - chromic (mention number: .....................) }\end{array}$} \\
\hline - vicryl (mention number: ......................) & & & & \\
\hline - dexon (mention number: .....................) & & & & \\
\hline $\begin{array}{l}\text { a. Why this type of suture material was used (ask doctor } \\
\text { if possible)? }\end{array}$ & & & & \\
\hline
\end{tabular}




\begin{tabular}{|c|c|c|c|c|}
\hline & Yes & No & NA & Code \\
\hline \multicolumn{5}{|l|}{ 115- Episiotomy repair: } \\
\hline \multicolumn{5}{|l|}{ a. Vaginal layer } \\
\hline \multicolumn{5}{|l|}{ - continuous } \\
\hline \multicolumn{5}{|l|}{ - interrupted } \\
\hline \multicolumn{5}{|l|}{ - interlocking } \\
\hline \multicolumn{5}{|l|}{ b. perineal muscles } \\
\hline \multicolumn{5}{|l|}{ - continuous } \\
\hline \multicolumn{5}{|l|}{ - interrupted } \\
\hline \multicolumn{5}{|l|}{ - interlocking } \\
\hline \multicolumn{5}{|l|}{ c. skin } \\
\hline \multicolumn{5}{|l|}{ - continuous subcuticular } \\
\hline \multicolumn{5}{|l|}{ - interrupted inverted } \\
\hline \multicolumn{5}{|l|}{ - interlocking } \\
\hline \multicolumn{5}{|l|}{$\begin{array}{l}\text { 116- Did a doctor perform a per rectum exam after finishing the } \\
\text { episiotomy repair?* }\end{array}$} \\
\hline \multicolumn{5}{|l|}{ 117- Was uterine exploration done?* } \\
\hline \multicolumn{5}{|l|}{$\begin{array}{l}\text { If yes, } \\
\text { a. as routine? }\end{array}$} \\
\hline \multicolumn{5}{|l|}{ b. because of missing placental parts? } \\
\hline \multicolumn{5}{|l|}{ c. using sterile gauze? } \\
\hline \multicolumn{5}{|l|}{ d. was anesthesia used for this purpose? } \\
\hline \multicolumn{5}{|l|}{ e. if yes, What type of anesthesia was used? ............... } \\
\hline \multicolumn{5}{|l|}{ 118- Did the delivering doctor congratulate the lady after the delivery? } \\
\hline \multicolumn{5}{|l|}{ 119- Did someone clean the lady? } \\
\hline \multicolumn{5}{|l|}{ 120- Was some kind of pad provided to the lady? } \\
\hline \multicolumn{5}{|l|}{ 121- Was the lady well covered? } \\
\hline \multicolumn{5}{|l|}{$\begin{array}{l}\text { 122- Was the lady lying in the lithotomy position after these } \\
\text { procedures were finished?* }\end{array}$} \\
\hline \multicolumn{5}{|l|}{$\begin{array}{l}\text { If yes, } \\
\text { a. for how long? ............................... }\end{array}$} \\
\hline $\begin{array}{l}\text { 123- What time is it now (as soon as the delivering doctor finished } \\
\text { intervening)?* }\end{array}$ & & & & \\
\hline
\end{tabular}




\begin{tabular}{|c|c|c|c|c|}
\hline & Yes & No & NA & Code \\
\hline \multicolumn{5}{|l|}{ 124- Was the baby given to the mother to hold in the delivery room? } \\
\hline \multicolumn{5}{|l|}{ 125- At what time was the lady given the baby?* } \\
\hline 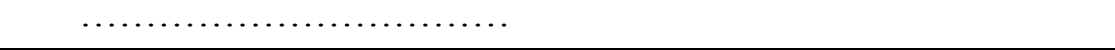 & & & & \\
\hline \multicolumn{5}{|l|}{ 126- Was the resuscitation data written down in the delivery room? } \\
\hline \multicolumn{5}{|l|}{ 127- What was the sex of the baby? } \\
\hline \multicolumn{5}{|l|}{ - male } \\
\hline \multicolumn{5}{|l|}{ - female } \\
\hline 128- Did the delivering doctor write the delivery summary in the file? & & & & \\
\hline
\end{tabular}




\section{Comments}




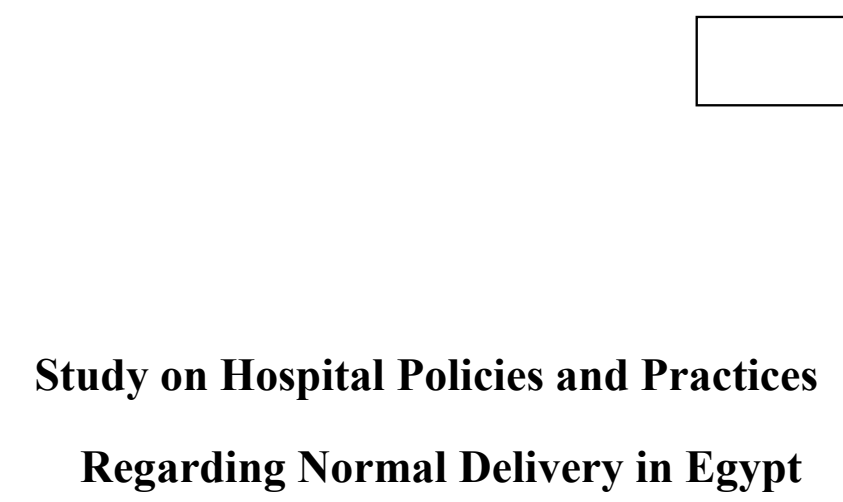

\section{$\underline{\text { Post-Labor Observation Checklist }}$}

Department:

Observer's name:

Date of observation:

Beginning of observation:

End of observation:

Name of the patient:

Patient's number from file:

This part of the study will be conducted by means of observation and record audit of Ob/Gyn physician in the Delivery room.

GIVE THE CHECKLIST TO THE OBSERVER IN THE POST LABOR ROOM TO CONTINUE 
POST-LABOR OBSERVATION

\begin{tabular}{|c|c|c|c|c|}
\hline & Yes & No & NA & Code \\
\hline \multicolumn{5}{|l|}{ 129- Write the exact time of arrival to the post labor war* } \\
\hline \multicolumn{5}{|l|}{ This question is not to be filled by the observer } \\
\hline \multicolumn{5}{|c|}{$\begin{array}{l}\text { 130- Was the interval between the time when a doctor finished } \\
\text { intervening \& time of arrival to the post labor ward } \\
\text { appropriate? }\end{array}$} \\
\hline \multicolumn{5}{|c|}{$\begin{array}{l}\text { 131- Was the lady transferred to the Post-labor ward accompanied } \\
\text { by the baby? }\end{array}$} \\
\hline \multicolumn{5}{|l|}{ a. If not, why not? } \\
\hline \multicolumn{5}{|l|}{ 132- Was the bed: } \\
\hline \multicolumn{5}{|l|}{ a. ready } \\
\hline \multicolumn{5}{|l|}{ b. clean } \\
\hline \multicolumn{5}{|l|}{ c. covered with a bed sheet } \\
\hline \multicolumn{5}{|l|}{ d. covered with a blanket } \\
\hline \multicolumn{5}{|l|}{ e. provided with a pillow } \\
\hline \multicolumn{5}{|c|}{$\begin{array}{l}\text { 133- Were there partitions or curtains between each bed for } \\
\text { privacy? }\end{array}$} \\
\hline \multicolumn{5}{|l|}{ 134- Did someone: } \\
\hline \multicolumn{5}{|l|}{ a. welcome her? } \\
\hline \multicolumn{5}{|l|}{ b. check the lady's personal data? } \\
\hline \multicolumn{5}{|l|}{ c. check the nametag of the baby? } \\
\hline \multicolumn{5}{|l|}{ d. review her delivery summary? } \\
\hline \multicolumn{5}{|l|}{ e. review the post partum prescribed order? } \\
\hline \multicolumn{5}{|l|}{ f. explain what would be done? } \\
\hline \multicolumn{5}{|l|}{ g. encourage the lady to start breastfeeding?* } \\
\hline h. was she encouraged to drink? & & & & \\
\hline
\end{tabular}




\begin{tabular}{|c|c|c|c|c|}
\hline \multirow{2}{*}{$\begin{array}{l}\text { 135- a. At what time did the lady put the baby on her breast } \\
\text { the first time?* }\end{array}$} & Yes & No & NA & Code \\
\hline & & & & \\
\hline \multicolumn{5}{|l|}{ b. On whose instructions? (ask the lady)* } \\
\hline \multicolumn{5}{|l|}{ 136- Did the lady drink anything? } \\
\hline \multicolumn{5}{|l|}{$\begin{array}{l}\text { If yes, } \\
\text { a. what? }\end{array}$} \\
\hline \multicolumn{5}{|l|}{ b. when? ..................................... } \\
\hline \multicolumn{5}{|l|}{ c. who provided it? } \\
\hline \multicolumn{5}{|l|}{ d. did she pay for it? } \\
\hline \multicolumn{5}{|l|}{ 137- Did the lady eat anything? } \\
\hline \multicolumn{5}{|l|}{ If yes, } \\
\hline \multicolumn{5}{|l|}{ b. when? ............................................ } \\
\hline \multicolumn{5}{|l|}{ c. who provided it? ............................... } \\
\hline \multicolumn{5}{|l|}{ d. did she pay for it? } \\
\hline \multicolumn{5}{|l|}{$\begin{array}{l}\text { 138- Did the lady need anything else during her stay in the post } \\
\text { labor ward?* }\end{array}$} \\
\hline \multicolumn{5}{|l|}{$\begin{array}{l}\text { a. If yes, } \\
\text { - pain relief }\end{array}$} \\
\hline \multicolumn{5}{|l|}{ - use the toilet } \\
\hline \multicolumn{5}{|l|}{ - have any concern about the baby } \\
\hline \multicolumn{5}{|l|}{ - have any concern about her family } \\
\hline \multicolumn{5}{|l|}{ - want to move around } \\
\hline \multicolumn{5}{|l|}{ - want to go home } \\
\hline \multicolumn{5}{|l|}{$\begin{array}{l}\text { - any questions about her health whether now or when } \\
\text { she goes home }\end{array}$} \\
\hline \multicolumn{5}{|l|}{ - other: ....................................... } \\
\hline 139- Where was the baby kept while in the post labor ward? & & & & \\
\hline
\end{tabular}




\begin{tabular}{|c|c|c|c|c|c|c|c|}
\hline & Yes & No & By who & Time* & $\begin{array}{l}\text { Recorded } \\
\text { the finding }\end{array}$ & $\begin{array}{l}\text { Noted } \\
\text { the time }\end{array}$ & Signed \\
\hline \multicolumn{8}{|l|}{$\begin{array}{l}\text { 140- When a doctor saw the lady, did s/he check:* } \\
\text { a. pulse }\end{array}$} \\
\hline \multicolumn{8}{|l|}{ b. blood pressure } \\
\hline \multicolumn{8}{|l|}{ c. temperature } \\
\hline \multicolumn{8}{|l|}{ d. fundal height } \\
\hline \multicolumn{8}{|l|}{ e. uterine tone } \\
\hline \multicolumn{8}{|l|}{ f. amount of vaginal bleeding } \\
\hline \multicolumn{8}{|l|}{ g. perineal repair if present } \\
\hline \multicolumn{8}{|c|}{ 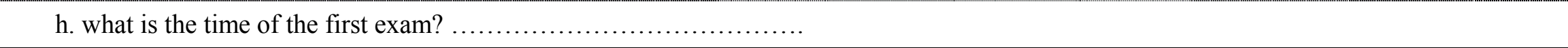 } \\
\hline \multicolumn{8}{|l|}{$\begin{array}{l}\text { 141- Was the lady surrounded by a partition or a curtain } \\
\text { during the exam? }\end{array}$} \\
\hline $\begin{array}{l}\text { 142- Was the lady covered during the examination? } \\
\text { (was privacy respected) }\end{array}$ & & & & & & & \\
\hline
\end{tabular}


If a vaginal exam was done:

\begin{tabular}{|c|c|c|c|c|}
\hline & Yes & No & NA & Code \\
\hline \multicolumn{5}{|l|}{ 143- Was a vaginal exam done? } \\
\hline \multicolumn{5}{|l|}{ a. If yes, why? } \\
\hline \multicolumn{5}{|l|}{ b. at what time?* } \\
\hline \multicolumn{5}{|l|}{$\begin{array}{l}\text { 144- If a doctor examined the lady vaginally, did s/he: } \\
\text { a. wash his/her hands? }\end{array}$} \\
\hline \multicolumn{5}{|l|}{$\begin{array}{l}\text { b. wear gloves? } \\
\text { - sterile }\end{array}$} \\
\hline \multicolumn{5}{|l|}{ - disposable } \\
\hline \multicolumn{5}{|l|}{ c. use antiseptic solution? } \\
\hline \multicolumn{5}{|l|}{ d. explain the examination procedure? } \\
\hline \multicolumn{5}{|l|}{$\begin{array}{l}\text { 145- After finishing the examination, did a doctor: } \\
\text { a. throw the contaminated items in the trashcan? }\end{array}$} \\
\hline \multicolumn{5}{|l|}{ b. if not, where were they thrown? } \\
\hline \multicolumn{5}{|l|}{ c. wash his/her hands? } \\
\hline \multicolumn{5}{|l|}{ d. share the examination findings with the lady? } \\
\hline \multicolumn{5}{|l|}{ e. share the findings with: } \\
\hline \multicolumn{5}{|l|}{ 1. the nurse } \\
\hline \multicolumn{5}{|l|}{ 2. the assisting doctor } \\
\hline \multicolumn{5}{|l|}{ 146- Did a doctor record: } \\
\hline \multicolumn{5}{|l|}{ a. the date of the examination? } \\
\hline \multicolumn{5}{|l|}{ b. the time of the examination? } \\
\hline \multicolumn{5}{|l|}{ c. the examination findings? } \\
\hline \multicolumn{5}{|l|}{ d. the orders to be followed by the nurse in charge? } \\
\hline e. the signature? & & & & \\
\hline
\end{tabular}




\begin{tabular}{|c|c|c|c|c|}
\hline & Yes & No & NA & Code \\
\hline \multicolumn{5}{|l|}{ 147- Was the baby examined?* } \\
\hline \multicolumn{5}{|c|}{$\begin{array}{l}\text { If yes, } \\
\text { a. did a doctor wash his/her hands before examining the baby? }\end{array}$} \\
\hline \multicolumn{5}{|c|}{ b. did a doctor explain the findings of the exam to the lady? } \\
\hline \multicolumn{5}{|c|}{ 148- In the post labor room was the baby fed within the first hour? } \\
\hline \multicolumn{5}{|l|}{$\begin{array}{l}\text { 149- What was the baby fed?* } \\
\text { - breast milk }\end{array}$} \\
\hline \multicolumn{5}{|l|}{ - sugary water } \\
\hline \multicolumn{5}{|l|}{ - formula } \\
\hline - other $\ldots \ldots \ldots \ldots \ldots \ldots \ldots \ldots \ldots$ & & & & \\
\hline
\end{tabular}

150- Before going home was the lady instructed about the danger signs and symptoms that may arise during the postpartum period:*
a. hemorrhage
b. fever
c. abdominal pain
d. offensive vaginal discharge?
e. lower limb edema, pain \& redness?

151- Before she was discharged, was the lady given information about:*

a. the duration of the postpartum period?

b. care of the episiotomy and hygiene?

c. how to table her medication?

d. early initiation of breast-feeding?

e. benefits of breast-feeding?

f. was the mother advised about:

1. positioning during breastfeeding

2. frequency of feeds

3. duration of feeds

4. was the mother asked if she wanted help with breastfeeding

g. breast-feeding problems?

h. maternal nutritional demands?

i. family planning advice?

j. when to come back for the clinic visit?

k. the baby immunization schedule? 


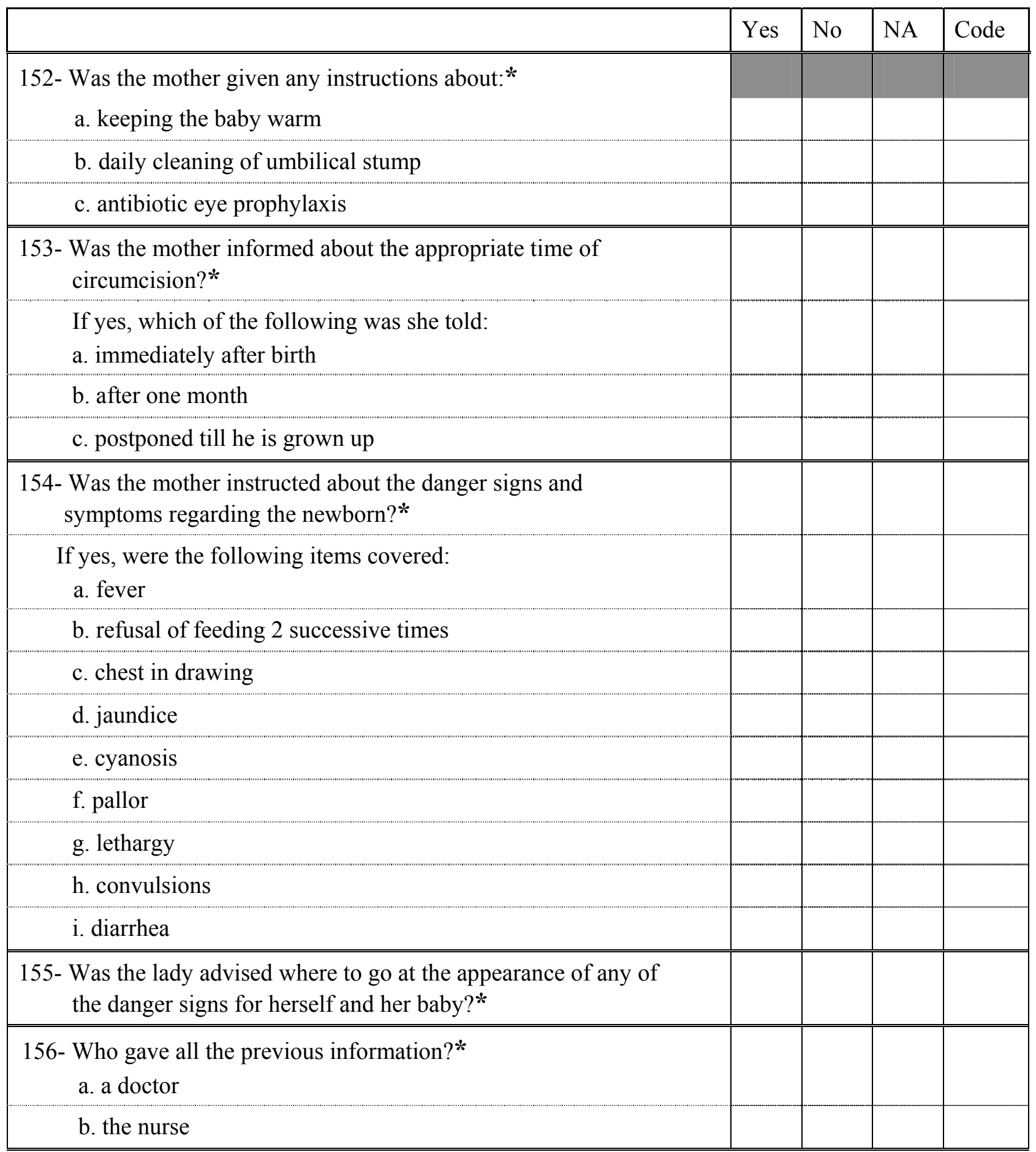




\begin{tabular}{|c|c|c|c|c|}
\hline & Yes & No & NA & Code \\
\hline \multicolumn{5}{|l|}{ 157- Were all instructions given to the mother: } \\
\hline \multicolumn{5}{|l|}{ a. orally } \\
\hline \multicolumn{5}{|l|}{ b. written } \\
\hline \multicolumn{5}{|l|}{ c. pamphlets/brochures } \\
\hline \multicolumn{5}{|l|}{ d. booklets } \\
\hline \multicolumn{5}{|l|}{ e. posters } \\
\hline \multicolumn{5}{|l|}{ f. flip charts } \\
\hline \multicolumn{5}{|l|}{ g. models } \\
\hline \multicolumn{5}{|l|}{ h. others:............................ } \\
\hline \multicolumn{5}{|l|}{ 158- Was the lady provided with a discharge summary?* } \\
\hline \multicolumn{5}{|l|}{$\begin{array}{l}\text { 159- Did the lady's discharge summary include: } \\
\text { a. the baby's weight }\end{array}$} \\
\hline \multicolumn{5}{|l|}{ b. medications for the baby } \\
\hline \multicolumn{5}{|l|}{ c. type of nutrition } \\
\hline \multicolumn{5}{|l|}{ 160- When was the last exam before the lady was discharged?* } \\
\hline \multicolumn{5}{|l|}{ a. what was the discharging doctor's rank? } \\
\hline \multicolumn{5}{|l|}{ 161- Was an antibiotic prescribed for the mother? } \\
\hline \multicolumn{5}{|l|}{ a. what was it? ................................ } \\
\hline \multicolumn{5}{|l|}{ b. were any other medications prescribed for the mother? } \\
\hline \multicolumn{5}{|l|}{ 162- At what time was she discharged?* } \\
\hline \multicolumn{5}{|l|}{ This question is not to be filled by the observer } \\
\hline 163- Was the time between delivery \& discharge acceptable? & & & & \\
\hline
\end{tabular}

\section{THANK YOU}




\section{Comments:}




\section{3- Vaginal examination:* SHADE EACH BOX ONLY IF "YES"}

\begin{tabular}{|l|}
\hline $\begin{array}{l}\text { A. Examination number }= \\
\text { Time: }{ }^{*} \\
\text { Rank of Doctor: } \\
\text { Did a doctor? }\end{array}$ \\
\hline 1. Introduce himself: - by name \\
\hline - by rank \\
\hline 2. Review pre-existing data \\
\hline 3. Ask permission to examine her $\square$ \\
\hline 4. Ask her to empty her bladder* $\square$ \\
\hline \hline 5. Tell her what would be done \\
\hline 6. Wash his or her hands: - With water \\
\hline - With soap and water \\
\hline - With antiseptic solution \\
\hline 7. Wear gloves: - Sterile \\
\hline - Disposable not from packet \\
\hline
\end{tabular}

8. Use lubricant gel

9. Covered the lady during the exam

10. Throw contaminated items in the trash

11. a. Tell the lady the findings

b. Tell any staff

12.a. Explain the plan to be followed to the lady

b. Explain that pain relief is available*

13. a. Record findings $\square$

b. Note time

c. Sign

14. Cervical dilatation in $\mathrm{cms}$

15. Did the doctor wipe the perineal area with antiseptic solution
B. Examination number $=$

Time:*

Rank of Doctor:

Did a doctor?

1. Introduce himself: - by name

- by rank

2. Review pre-existing data

3. Ask permission to examine her

4. Ask her to empty her bladder*

5. Tell her what would be done

6. Wash his or her hands: - With water

- With soap and water

- With antiseptic solution

7. Wear gloves: - Sterile

- Disposable not from packet

- Disposable from the packet

8. Use lubricant gel

9. Covered the lady during the exam

10. Throw contaminated items in the trash $\square$

11. a. Tell the lady the findings

b. Tell any staff

12.a. Explain the plan to be followed to the lady

b. Explain that pain relief is available*

13. a. Record findings

b. Note time

c. Sign

14. Cervical dilatation in $\mathrm{cms}$

15. Did the doctor wipe the perineal area with antiseptic solution 


\begin{tabular}{|c|c|}
\hline $\begin{array}{l}\text { C. Examination number }= \\
\text { Time: } \\
\text { Rank of Doctor: } \\
\text { Did a doctor? }\end{array}$ & $\begin{array}{l}\text { D. Examination number }= \\
\text { Time: } \\
\text { Rank of Doctor: } \\
\text { Did a doctor? }\end{array}$ \\
\hline 1. Introduce himself: - by name & 1. Introduce himself: - by name \\
\hline - by rank & - by rank \\
\hline 2. Review pre-existing data & 2. Review pre-existing data \\
\hline 3. Ask permission to examine her $\square$ & 3. Ask permission to examine her \\
\hline 4. Ask her to empty her bladder & 4. Ask her to empty her bladder \\
\hline 5. Tell her what would be done & 5. Tell her what would be done \\
\hline 6. Wash his or her hands: - With water & 6. Wash his or her hands: - With water \\
\hline - With soap and water & - With soap and water \\
\hline - With antiseptic solution & - With antiseptic solution \\
\hline 7. Wear gloves: - Sterile & 7. Wear gloves: - Sterile \\
\hline - Disposable not from packet & - Disposable not from packet \\
\hline - Disposable from the packet & - Disposable from the packet \\
\hline 8. Use lubricant gel $\square$ & 8. Use lubricant gel \\
\hline 9. Covered the lady during the exam $\square$ & 9. Covered the lady during the exam \\
\hline 10. Throw contaminated items in the trash & 10. Throw contaminated items in the trash \\
\hline 11. a. Tell the lady the findings $\square$ & 11. a. Tell the lady the findings \\
\hline b. Tell any staff & b. Tell any staff \\
\hline 12.a. Explain the plan to be followed to the lady & 12.a. Explain the plan to be followed to the lady \\
\hline b. Explain that pain relief is available & b. Explain that pain relief is available \\
\hline 13. a. Record findings $\square$ & 13. a. Record findings $\square$ \\
\hline b. Note time & b. Note time \\
\hline c. Sign & c. Sign \\
\hline 14. Cervical dilatation in $\mathrm{cms}$ & 14. Cervical dilatation in $\mathrm{cms}$ \\
\hline $\begin{array}{l}\text { 15. Did the doctor wipe the perineal area with } \\
\text { antiseptic solution }\end{array}$ & $\begin{array}{l}\text { 15. Did the doctor wipe the perineal area with } \\
\text { antiseptic solution }\end{array}$ \\
\hline
\end{tabular}




\begin{tabular}{|c|c|}
\hline $\begin{array}{l}\text { E. Examination number }= \\
\text { Time: } \\
\text { Rank of Doctor: } \\
\text { Did a doctor? }\end{array}$ & $\begin{array}{l}\text { F. Examination number }= \\
\text { Time: } \\
\text { Rank of Doctor: } \\
\text { Did a doctor? }\end{array}$ \\
\hline 1. Introduce himself: - by name & 1. Introduce himself: - by name \\
\hline - by rank & - by rank \\
\hline 2. Review pre-existing data & 2. Review pre-existing data \\
\hline 3. Ask permission to examine her $\square$ & 3. Ask permission to examine her \\
\hline 4. Ask her to empty her bladder & 4. Ask her to empty her bladder \\
\hline 5. Tell her what would be done $\square$ & 5. Tell her what would be done \\
\hline 6. Wash his or her hands: - With water & 6. Wash his or her hands: - With water \\
\hline - With soap and water & - With soap and water \\
\hline - With antiseptic solution & - With antiseptic solution \\
\hline 7. Wear gloves: - Sterile & 7. Wear gloves: - Sterile \\
\hline - Disposable not from packet & - Disposable not from packet \\
\hline - Disposable from the packet & - Disposable from the packet \\
\hline 8. Use lubricant gel $\square$ & 8. Use lubricant gel $\square$ \\
\hline 9. Covered the lady during the exam $\square$ & 9. Covered the lady during the exam \\
\hline 10. Throw contaminated items in the trash & 10. Throw contaminated items in the trash \\
\hline 11. a. Tell the lady the findings $\square$ & 11. a. Tell the lady the findings $\square$ \\
\hline b. Tell any staff & b. Tell any staff \\
\hline 12.a. Explain the plan to be followed to the lady & 12.a. Explain the plan to be followed to the lady \\
\hline b. Explain that pain relief is available & b. Explain that pain relief is available \\
\hline 13. a. Record findings $\square$ & 13. a. Record findings $\square$ \\
\hline b. Note time & b. Note time \\
\hline c. Sign & c. Sign \\
\hline 14. Cervical dilatation in $\mathrm{cms}$ & 14. Cervical dilatation in $\mathrm{cms}$ \\
\hline $\begin{array}{l}\text { 15. Did the doctor wipe the perineal area with } \\
\text { antiseptic solution }\end{array}$ & $\begin{array}{l}\text { 15. Did the doctor wipe the perineal area with } \\
\text { antiseptic solution }\end{array}$ \\
\hline
\end{tabular}




\begin{tabular}{|c|c|}
\hline $\begin{array}{l}\text { G. Examination number }= \\
\text { Time: } \\
\text { Rank of Doctor: } \\
\text { Did a doctor? }\end{array}$ & $\begin{array}{l}\text { H. Examination number }= \\
\text { Time: } \\
\text { Rank of Doctor: } \\
\text { Did a doctor? }\end{array}$ \\
\hline 1. Introduce himself: - by name & 1. Introduce himself: - by name \\
\hline - by rank & - by rank \\
\hline 2. Review pre-existing data & 2. Review pre-existing data \\
\hline 3. Ask permission to examine her $\square$ & 3. Ask permission to examine her \\
\hline 4. Ask her to empty her bladder & 4. Ask her to empty her bladder \\
\hline 5. Tell her what would be done & 5. Tell her what would be done \\
\hline 6. Wash his or her hands: - With water & 6. Wash his or her hands: - With water \\
\hline - With soap and water & - With soap and water \\
\hline - With antiseptic solution & - With antiseptic solution \\
\hline 7. Wear gloves: - Sterile & 7. Wear gloves: - Sterile \\
\hline - Disposable not from packet & - Disposable not from packet \\
\hline - Disposable from the packet & - Disposable from the packet \\
\hline 8. Use lubricant gel $\square$ & 8. Use lubricant gel $\square$ \\
\hline 9. Covered the lady during the exam $\square$ & 9. Covered the lady during the exam \\
\hline 10. Throw contaminated items in the trash $\square$ & 10. Throw contaminated items in the trash \\
\hline 11. a. Tell the lady the findings $\square$ & 11. a. Tell the lady the findings \\
\hline b. Tell any staff & b. Tell any staff \\
\hline 12.a. Explain the plan to be followed to the lady & 12.a. Explain the plan to be followed to the lady \\
\hline b. Explain that pain relief is available & b. Explain that pain relief is available \\
\hline 13. a. Record findings $\square$ & 13. a. Record findings $\square$ \\
\hline b. Note time & b. Note time \\
\hline c. Sign & c. Sign \\
\hline 14. Cervical dilatation in $\mathrm{cms}$ & 14. Cervical dilatation in $\mathrm{cms}$ \\
\hline $\begin{array}{l}\text { 15. Did the doctor wipe the perineal area with } \\
\text { antiseptic solution }\end{array}$ & $\begin{array}{l}\text { 15. Did the doctor wipe the perineal area with } \\
\text { antiseptic solution }\end{array}$ \\
\hline
\end{tabular}




\begin{tabular}{|c|c|}
\hline $\begin{array}{l}\text { I. Examination number }= \\
\text { Time: } \\
\text { Rank of Doctor: } \\
\text { Did a doctor? }\end{array}$ & $\begin{array}{l}\text { J. Examination number }= \\
\text { Time: } \\
\text { Rank of Doctor: } \\
\text { Did a doctor? }\end{array}$ \\
\hline 1. Introduce himself: - by name & 1. Introduce himself: - by name \\
\hline - by rank & - by rank \\
\hline 2. Review pre-existing data & 2. Review pre-existing data \\
\hline 3. Ask permission to examine her & 3. Ask permission to examine her \\
\hline 4. Ask her to empty her bladder & 4. Ask her to empty her bladder \\
\hline 5. Tell her what would be done & 5. Tell her what would be done \\
\hline 6. Wash his or her hands: - With water & 6. Wash his or her hands: - With water \\
\hline - With soap and water & - With soap and water \\
\hline - With antiseptic solution & - With antiseptic solution \\
\hline 7. Wear gloves: - Sterile & 7. Wear gloves: - Sterile \\
\hline - Disposable not from packet & - Disposable not from packet \\
\hline - Disposable from the packet & - Disposable from the packet \\
\hline 8. Use lubricant gel $\square$ & 8. Use lubricant gel \\
\hline 9. Covered the lady during the exam $\square$ & 9. Covered the lady during the exam \\
\hline 10. Throw contaminated items in the trash $\square$ & 10. Throw contaminated items in the trash \\
\hline 11. a. Tell the lady the findings $\square$ & 11. a. Tell the lady the findings $\square$ \\
\hline b. Tell any staff & b. Tell any staff \\
\hline 12.a. Explain the plan to be followed to the lady & 12.a. Explain the plan to be followed to the lady \\
\hline b. Explain that pain relief is available & b. Explain that pain relief is available \\
\hline 13. a. Record findings $\square$ & 13. a. Record findings $\square$ \\
\hline b. Note time & b. Note time \\
\hline c. Sign & c. Sign \\
\hline 14. Cervical dilatation in $\mathrm{cms}$ & 14. Cervical dilatation in $\mathrm{cms}$ \\
\hline $\begin{array}{l}\text { 15. Did the doctor wipe the perineal area with } \\
\text { antiseptic solution }\end{array}$ & $\begin{array}{l}\text { 15. Did the doctor wipe the perineal area with } \\
\text { antiseptic solution }\end{array}$ \\
\hline
\end{tabular}




\begin{tabular}{|c|c|}
\hline $\begin{array}{l}\text { K. Examination number }= \\
\text { Time: } \\
\text { Rank of Doctor: } \\
\text { Did a doctor? }\end{array}$ & $\begin{array}{l}\text { L. Examination number }= \\
\text { Time: } \\
\text { Rank of Doctor: } \\
\text { Did a doctor? }\end{array}$ \\
\hline 1. Introduce himself: - by name & 1. Introduce himself: - by name \\
\hline - by rank & - by rank \\
\hline 2. Review pre-existing data & 2. Review pre-existing data \\
\hline 3. Ask permission to examine her & 3. Ask permission to examine her \\
\hline 4. Ask her to empty her bladder & 4. Ask her to empty her bladder \\
\hline 5. Tell her what would be done & 5. Tell her what would be done \\
\hline 6. Wash his or her hands: - With water & 6. Wash his or her hands: - With water \\
\hline - With soap and water & - With soap and water \\
\hline - With antiseptic solution & - With antiseptic solution \\
\hline 7. Wear gloves: - Sterile & 7. Wear gloves: - Sterile \\
\hline - Disposable not from packet & - Disposable not from packet \\
\hline - Disposable from the packet & - Disposable from the packet \\
\hline 8. Use lubricant gel $\square$ & 8. Use lubricant gel \\
\hline 9. Covered the lady during the exam $\square$ & 9. Covered the lady during the exam $\square$ \\
\hline 10. Throw contaminated items in the trash & 10. Throw contaminated items in the trash \\
\hline 11. a. Tell the lady the findings $\square$ & 11. a. Tell the lady the findings \\
\hline b. Tell any staff & b. Tell any staff \\
\hline 12.a. Explain the plan to be followed to the lady & 12.a. Explain the plan to be followed to the lady \\
\hline b. Explain that pain relief is available & b. Explain that pain relief is available \\
\hline 13. a. Record findings $\square$ & 13. a. Record findings $\square$ \\
\hline b. Note time & b. Note time \\
\hline c. Sign & c. Sign \\
\hline 14. Cervical dilatation in $\mathrm{cms}$ & 14. Cervical dilatation in $\mathrm{cms}$ \\
\hline $\begin{array}{l}\text { 15. Did the doctor wipe the perineal area } \square^{\text {h }} \\
\text { antiseptic solution }\end{array}$ & $\begin{array}{l}\text { 15. Did the doctor wipe the perineal area with } \\
\text { antiseptic solution }\end{array}$ \\
\hline
\end{tabular}


Monitoring \& Medications: Please put a $(\sqrt{ }$ ) or details EVERY TIME one of the following is done \& note the time 37- Table of labor progress monitoring $\&$ types of fluids or medications ordered by a doctor*

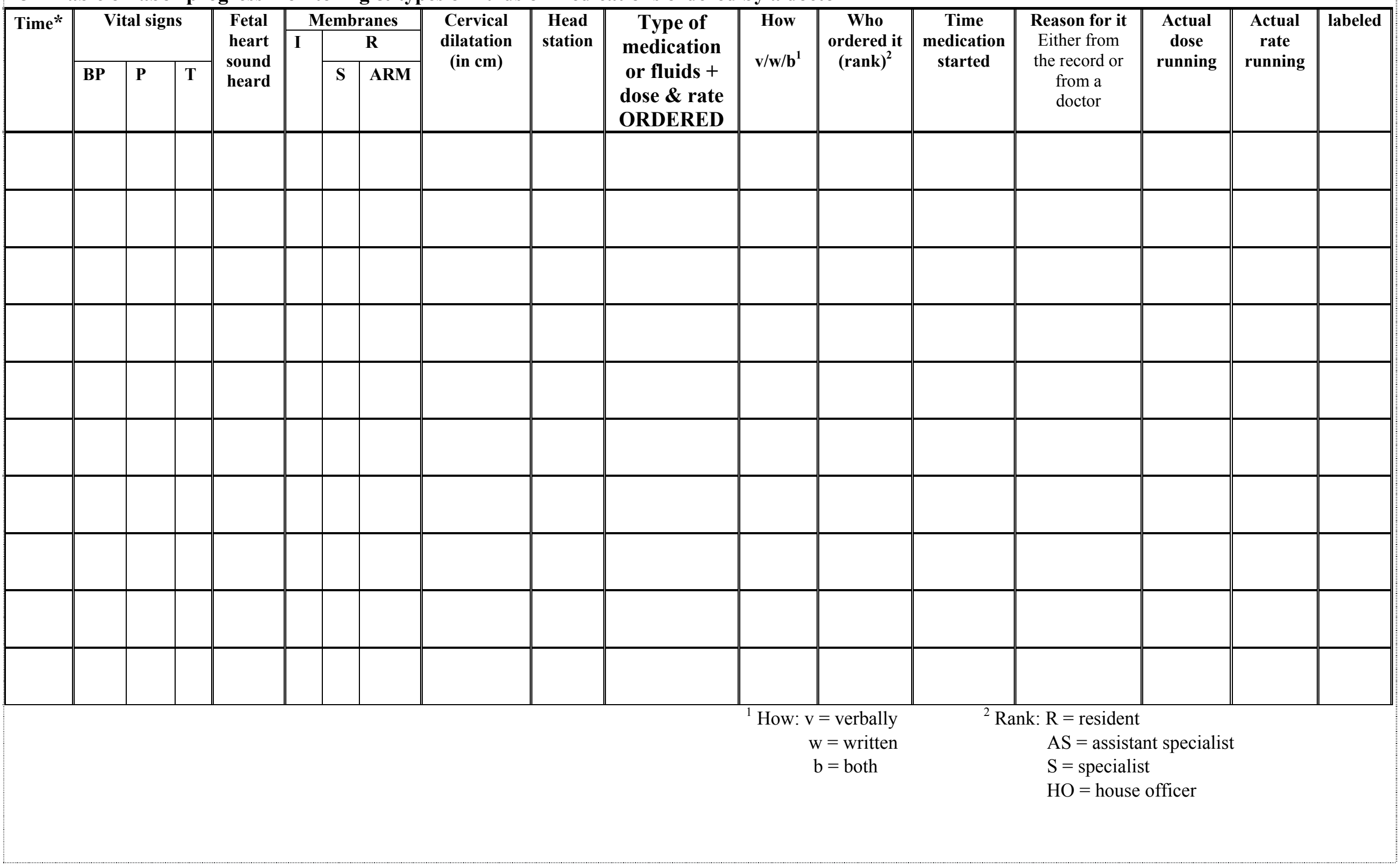




\begin{tabular}{|c|c|c|c|c|c|c|c|c|c|c|c|c|c|c|c|c|c|}
\hline \multirow[t]{3}{*}{ Time } & \multirow{2}{*}{\multicolumn{3}{|c|}{ Vital signs }} & \multirow{3}{*}{$\begin{array}{c}\text { Fetal } \\
\text { heart } \\
\text { sound } \\
\text { heard }\end{array}$} & \multicolumn{3}{|c|}{ Membranes } & \multirow{3}{*}{$\begin{array}{c}\text { Cervical } \\
\text { dilatation } \\
\text { (in cm) }\end{array}$} & \multirow{3}{*}{$\begin{array}{c}\text { Head } \\
\text { station }\end{array}$} & \multirow{3}{*}{$\begin{array}{c}\text { Type of } \\
\text { medication } \\
\text { or fluids }+ \\
\text { dose \& rate } \\
\text { ORDERED } \\
\end{array}$} & \multirow{3}{*}{$\begin{array}{c}\text { How } \\
\text { v/w/ } / \mathbf{b}^{1}\end{array}$} & \multirow{3}{*}{\begin{tabular}{|c|}
$\begin{array}{c}\text { Who } \\
\text { ordered it } \\
(\text { rank })^{2}\end{array}$ \\
\end{tabular}} & \multirow{3}{*}{$\begin{array}{c}\text { Time } \\
\text { medication } \\
\text { started }\end{array}$} & \multirow{3}{*}{$\begin{array}{l}\text { Reason for it } \\
\text { Either from } \\
\text { the record or } \\
\text { from a doctor }\end{array}$} & \multirow{3}{*}{$\begin{array}{c}\text { Actual } \\
\text { dose } \\
\text { running }\end{array}$} & \multirow{3}{*}{$\begin{array}{c}\text { Actual } \\
\text { rate } \\
\text { running }\end{array}$} & \multirow[t]{3}{*}{ labeled } \\
\hline & & & & & \multirow[t]{2}{*}{ I } & \multicolumn{2}{|c|}{$\mathbf{R}$} & & & & & & & & & & \\
\hline & BP & $\mathbf{P}$ & $\mathbf{T}$ & & & $\mathbf{S}$ & ARM & & & & & & & & & & \\
\hline & & & & & & & & & & & & & & & & & \\
\hline & & & & & & & & & & & & & & & & & \\
\hline & & & & & & & & & & & & & & & & & \\
\hline & & & & & & & & & & & & & & & & & \\
\hline & & & & & & & & & & & & & & & & & \\
\hline & & & & & & & & & & & & & & & & & \\
\hline & & & & & & & & & & & & & & & & & \\
\hline & & & & & & & & & & & & & & & & & \\
\hline & & & & & & & & & & & & & & & & & \\
\hline & & & & & & & & & & & & & & & & & \\
\hline & & & & & & & & & & & & & & & & & \\
\hline & & & & & & & & & & & ${ }^{1}$ How & $\begin{array}{l}v=\text { verbally } \\
w=\text { written } \\
b=\text { both }\end{array}$ & & $\begin{array}{r}\mathrm{R}=\text { residen } \\
\mathrm{AS}=\text { assist } \\
\mathrm{S}=\text { special } \\
\mathrm{HO}=\text { hous }\end{array}$ & $\begin{array}{l}\text { nt specialis } \\
t \\
\text { officer }\end{array}$ & & \\
\hline
\end{tabular}




\section{Interview with women up to time of discharge}

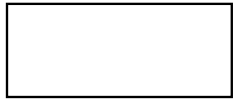

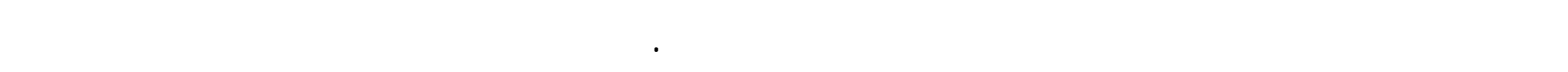

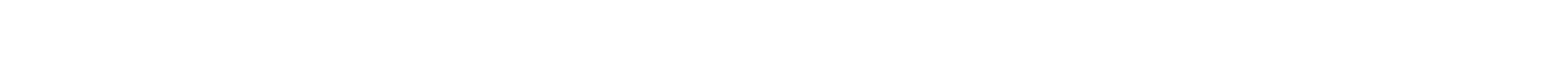
إزعاج ولا أعللسير العطل.

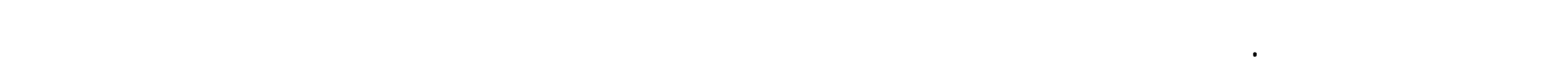
Congratulations, Can I ask you a few questions about the services offered by the hospital before you leave.

$$
\text { (No) } \mathrm{y} \square
$$

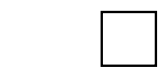

\section{(If no, please explain why?) (إذا لا الرجاءشرحسب الرفض)}

\section{1 مرتلحة دلوقتي ولا لسه تعبانة في حلجة؟} (Are you feeling comfortable now or is anything bothering you?)

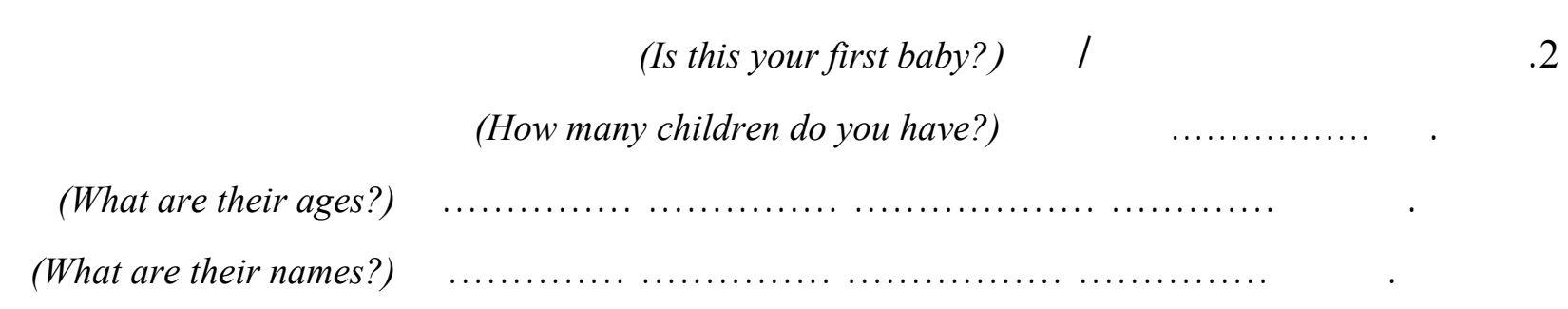




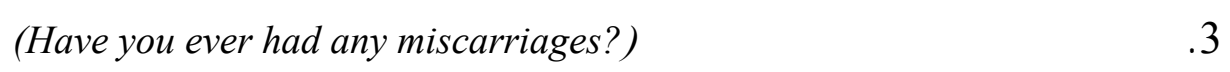

(Please take complete reproductive history including full term pregnanciesmiscarriages - neo-natal death and other significant problems such as infertility)

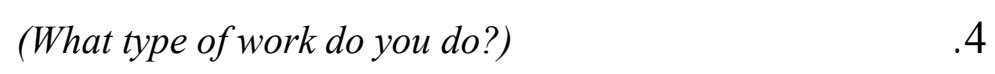

5. إيه لخرمرحلة تعليم وصلتي لها؟ (What level of education did you reach?)

6. زوج حضرنك بيشتغل إيه؟ (What is your husband's work?)

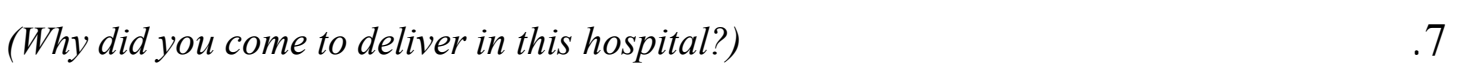

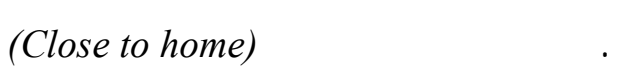

ب. ولدت هنا قبل كةة (Delivered here before)

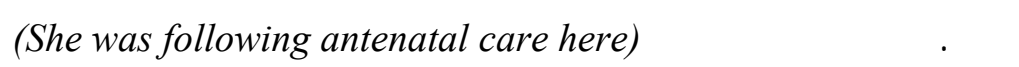

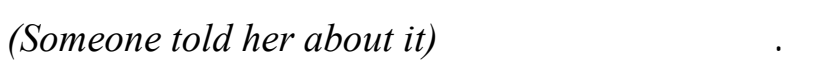

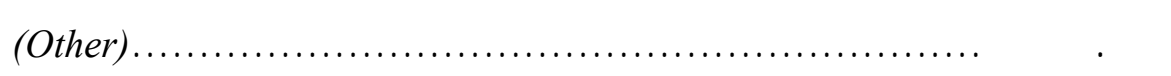

8. مين اللي ولدك، يعني تعرفي أسمه من وأنت فى العنبر؟

(Who delivered your baby i.e. do you know his/her name?)

(Was he/she good?)

أ. كلن كوبيس.

(How did s/he make you feel comfortable?) ب. ريطك في إيه.

(How did s/he make you feel uncomfortable?)

ج. تعبك في إيه. 
9. إيه اللى خلاكي ما ولدتيش في البيت؟ (ما هي مشاكل الو لادة في البيت؟) (What made you not deliver at home?(What are the problems of delivering at home))

(Did you deliver at home before?) أ. أنت ولاتي في البيت قبل كده؟.

10. الخدة هنا كويسة؟ (لكثر تقاصل ممكنة عن الخدة الصحية والفندقية وطريقة معلملة المريضة) (Is the service here good? (As much details as possible about the health services \& the treatment)) (What was good?) أ. إيه الكويس؟.

(What was bad?) ب. إيه الومش؟

11. قالوا لك حلجة عن صحة المولود؟................. (Did they tell you anything about the baby's health?

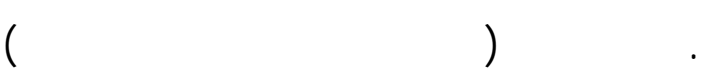

(What did they tell you? (Did they tell you about danger signs?))

(Who gave you this information?) ب.مين اللي أدلكي المعلوملت دي؟.

12. قالوا لك حلجة عن صحك أنت؟......................... (Did they tell you anything about your health?) أ. قالوا إيه؟ (هل قالوا لها عن علأمن الغطر)...

(What did they tell you? (Did they tell you about danger signs?))

(Who gave you this information?) ب.مين اللي أدلهي المعلومات دي؟ 


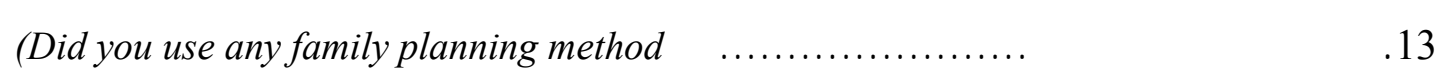
before?)

(What type of method did you use?(tell me about it)) أ. لخذت إيهى لحكي لي

14. لٔخيرا عايزه أسأك قفتكري إزاى ممكن يمسنوا الرعاية هنا في المستثف؟ (Finally, I want to ask you, in your opinion, how can services in this hospital be improved?) 


\section{APPENDIX B}

\section{GROUPING OF DATA VARIABLES BY QUESTION NUMBER}


This collection of tables provides a listing of the data collected (on the left), with the number of the corresponding question shown on the right.

$\mathrm{ER}=$ Emergency room $\quad \mathrm{DR}=$ Delivery room $\quad$ FHS $=$ Fetal heart sounds

\section{Demographic variables}

\begin{tabular}{|l|l|}
\hline Data & Question \# \\
\hline Age \& parity & P7 of the checklist \\
\hline Lady's education, occupation \& occupation of husband & Postpartum interview \\
\hline
\end{tabular}

\section{Caseload}

\begin{tabular}{|l|l|}
\hline Data & Question \# \\
\hline $\begin{array}{l}\text { Number of cases waiting in the waiting room at the time of } \\
\text { observation }\end{array}$ & P6 \\
\hline $\begin{array}{l}\text { Caseload during labor }=\text { doctor : patient }=1: 8 \\
\text { Average number of cases processed per day }=101 \\
\text { Average number of deliveries per day }=55\end{array}$ & From hospital records \\
$\left.\begin{array}{l}\text { Average number of patients } \\
\text { Maximum number of patients/ bed } \\
\begin{array}{l}\text { Number of empty beds over the 3 days } \\
\text { Percent of beds serving } 3 \text { or more women }\end{array}\end{array}\right\}$ Per shift & Timed map of beds \\
\hline Types of cases & \\
\hline
\end{tabular}


3. Facility preparedness

\begin{tabular}{|l|l|}
\hline Data & Question \# \\
\hline A printed form exists for history-taking in the ER & Q3 \\
\hline A printed form exists for history-taking in the prelabor ward & Q25 \\
\hline Preparation \& availability of equipment on the examination table & Q28,29 \\
\hline Apparatus used in FHS auscultation in the prelabor ward & Q32a \\
\hline Availability of pain relief & Q49 \\
\hline Instruments available in the DR \& sterilization & Q84,85,86 \\
\hline The delivering doctor's wear & Q87 \\
\hline The nurse's wear in the DR & Q88 \\
\hline Apparatus used in FHS auscultation in the delivery room & Q92 \\
\hline Availability of anesthesia & Q75 \\
\hline Adequate light provided for the episiotomy/tear repair & Q113b \\
\hline Types of sutures used for repair & Q114 \\
\hline Equipment available for the neonatal care at the time of delivery & Q98 \\
\hline The bed in the post labor ward & Q132 \\
\hline Partitions available between the beds in the post labor ward & Q133 \\
\hline The place where the baby was kept in the post labor ward & Q139 \\
\hline The lady's discharge summary & Q158,159 \\
\hline
\end{tabular}

\section{Assessment}

\begin{tabular}{|l|l|}
\hline Data & Question \# \\
\hline History-taking in the ER & Q2,3 \\
\hline History-taking in the $1^{\text {st }}$ stage of labor & Q25 \\
\hline General examination \& FHS in the ER & Q5,6,7 \\
\hline General examination in the $1^{\text {st }}$ stage of labor & Q30,31 \\
\hline Vaginal exam in the ER & Q12 \\
\hline
\end{tabular}

5. Management of the $1^{\text {st }}$ stage of labor

\begin{tabular}{|l|l|}
\hline Data & Question \# \\
\hline FHS in the $1^{\text {st }}$ stage of labor & $\begin{array}{l}\text { Q32 \& Table Q37 on } \\
\text { P46,47 }\end{array}$ \\
\hline Vaginal exam in the $1^{\text {st }}$ stage of labor & Table Q33 on P40-45 \\
\hline Number of different providers who examined the lady & Q55 \\
\hline Appropriateness of interval between vaginal exams & $\begin{array}{l}\text { Q40 \& Table Q33 on } \\
\text { P40-45 }\end{array}$ \\
\hline Oxytocin administration & Table Q37 on P46,47 \\
\hline IV line insertion & Q38 \\
\hline IV line insertion with aseptic technique & Q39 \\
\hline IV line checking & Q43 \\
\hline Appropriateness of oxytocin order in the $1^{\text {st }}$ stage of labor & $\begin{array}{l}\text { Q41 \& Table Q37 on } \\
\text { P46,47 }\end{array}$ \\
\hline Request for an enema \& perineal shaving & Q35 \\
\hline
\end{tabular}


6. Management of the $2^{\text {nd }}$ stage of labor

\begin{tabular}{|l|l|}
\hline Data & Question \# \\
\hline Position of delivery & Q62 \\
\hline Tying of the lady & Q63 \\
\hline Fundal pressure applied & Q70 \\
\hline Use of instruments & Q71 \\
\hline Episiotomy & Q73 \\
\hline Anesthesia & Q75,76 \\
\hline FHS in the $2^{\text {nd }}$ stage of labor & Q90 \\
\hline Pain relief & Q92 \\
\hline
\end{tabular}

\section{Management of the $3^{\text {rd }}$ stage of labor}

\begin{tabular}{|l|l|}
\hline Data & Question \# \\
\hline Management of the cord & Q94 \\
\hline Ecbolic ordered & Q95 \\
\hline Appropriateness of management of $3^{\text {rd }}$ stage of labor & $\begin{array}{l}\text { Q94, 95 \& Table Q37 } \\
\text { on P46,47 }\end{array}$ \\
\hline
\end{tabular}

\section{Pain relief}

\begin{tabular}{|l|l|}
\hline Data & Question \# \\
\hline Pain relief in the prelabor room & Q49 \\
\hline Pain relief in the delivery room & Q92 \\
\hline
\end{tabular}

\section{Recording}

\begin{tabular}{|l|l|}
\hline Data & Question \# \\
\hline Recording of history taken in the ER & Q3 \\
\hline Recording of history taken in the prelabor ward & Q25 \\
\hline Recording of general exam \& FHS in the ER & Q5,6,7 \\
\hline Recording of the vaginal exam done in the ER & Q12 \\
\hline Recording of the vaginal exam done in the prelabor ward & Table Q33 on P40-45 \\
\hline Labeling of IV infusion & Table Q37 on P46,47 \\
\hline Writing of the resuscitation data in the delivery room & Q126 \\
\hline Writing of the delivery summary in the delivery room & Q128 \\
\hline Writing of the Apgar score & Q104 \\
\hline Taking of the baby's footprint & Q106d \\
\hline Recording of the general exam in the postpartum ward & Q140 \& Q146 \\
\hline Content of discharge summary & Q158,159 \\
\hline
\end{tabular}


10. Infection control

\begin{tabular}{|l|l|}
\hline Data & Question \# \\
\hline Infection control before the vaginal exam done in the ER & Q8d,8e, Q10c \\
\hline Preparation of examination table equipment & Q29 \\
\hline $\begin{array}{l}\text { Infection control before the vaginal exam done in the prelabor } \\
\text { ward }\end{array}$ & $\begin{array}{l}\text { Table Q33 on } \\
\text { P40-45 }\end{array}$ \\
\hline IV line insertion under complete aseptic technique & Q39 \\
\hline Infection control in the delivery room & Q66,67 \\
\hline Uterine exploration done using gauze & Q117c \\
\hline Cleaning the lady after the delivery & Q119 \\
\hline Providing pad to the lady & Q120 \\
\hline Nasogastric tube opened for the baby or previously used & Q98e \\
\hline Infection control before the vaginal exam in the postpartum ward & Q144 \\
\hline Washing the hands before examining the baby & Q147a \\
\hline Doctor's clothes in the delivery room & Q87 \\
\hline Nurse's clothes in the delivery room & Q88 \\
\hline
\end{tabular}

\section{Communication}

\begin{tabular}{|l|l|}
\hline Data & Question \# \\
\hline Communication in the ER & Q4,Q8a,c,Q10a,Q11 \\
\hline Communication in the prelabor ward & Q26a,c,Q34c,d,e \\
\hline Doctor introduced him/herself & Q23 \\
\hline Calling the lady by her name & Q24 \\
\hline During the vaginal exams in the prelabor ward & Table Q33 on P40-45 \\
\hline $\begin{array}{l}\text { Instructions concerning eating, drinking \& movement given by } \\
\text { doctor in the prelabor ward }\end{array}$ & Q44,45,46,47,48 \\
\hline Asking \& responding to the lady's requests & Q50 \\
\hline Before transfer to the DR, instructions \& notifications & Q52 \\
\hline Introduction of the doctor in the DR & Q60 \\
\hline Explaining what would be done in the DR & Q61 \\
\hline Asking lady to push down \& explaining how \& when to push & Q68,69 \\
\hline Congratulating the lady & Q118 \\
\hline Informing the lady about episiotomoy repair & Q113a \\
\hline Welcome \& communication in the post labor ward & Q134 \\
\hline Instructing the lady to breastfeed & Q135b \\
\hline Communication during the postpartum exam & Q144d,Q145d,e,Q147b \\
\hline $\begin{array}{l}\text { Giving information about the danger signs \& symptoms that may } \\
\text { arise during the post partum period }\end{array}$ & Q150,Q151a-c \\
\hline Giving information about breastfeeding & Q151d-h \\
\hline Giving information about family planning & Q151i,j \\
\hline Giving information about the baby & Q151k,Q152,Q153 \\
\hline $\begin{array}{l}\text { Giving information about the danger signs \& symptoms regarding } \\
\text { the newborn }\end{array}$ & Q154,155 \\
\hline Information given by doctor / nurse & Q156 \\
\hline Information given to the lady in what form & Q157 \\
\hline
\end{tabular}


12. Continuous monitoring

\begin{tabular}{|l|l|}
\hline Data & Question \# \\
\hline Reviewing the admission data before the exam & Q18,19 \\
\hline General exam in the $1^{\text {st }}$ stage of labor & Q30,31 \\
\hline Checking the fetal heart sounds in the $1^{\text {st }}$ stage & $\begin{array}{l}\text { Q32 \& Table Q37 on } \\
\text { P46,47 }\end{array}$ \\
\hline Number of times a lady was examined vaginally & Table Q33 on P40-45 \\
\hline Number of different providers who examined the lady vaginally & Q55 \\
\hline Reviewing of pre-existing data of vaginal exams & Table Q33 on P40-45 \\
\hline Telling any staff the findings of the vaginal exams & Table Q33 on P40-45 \\
\hline Checking the IV line & Q43 \\
\hline Oxytocin administration \& FHS done appropriately & Table Q37 on P46,47 \\
\hline Checking the lady's file in the delivery room & Q58,59 \\
\hline FHS in the DR & Q92 \\
\hline Review of data in the post labor ward & Q134 \\
\hline General exam in the post labor ward & Q140 \\
\hline Postpartum vaginal exam & Q143 \\
\hline Examination of the baby & Q147 \\
\hline
\end{tabular}




\section{Hospital policies from the woman's perspective}

\begin{tabular}{|c|c|}
\hline Data & Question \# \\
\hline Before the vaginal exam in the ER, Dr. asked lady to bend her knees & Q8c \\
\hline Before the vaginal exam in the ER, Dr. covered the lady with a sheet & Q8g \\
\hline The rank of the doctor who examined the lady vaginally in the ER & Q9 \\
\hline The person who met the lady at the prelabor ward & Q16 \\
\hline The person who helped the lady to settle in the prelabor ward & Q17 \\
\hline Privacy in the prelabor ward & Q27 \\
\hline Request for an enema / shaving & Q35 \\
\hline Procedures before $\&$ during the vaginal exams in the prelabor ward & $\begin{array}{l}\text { from Table Q33 on } \\
\text { P40-45 }\end{array}$ \\
\hline $\begin{array}{l}\text { Instructions concerning eating, drinking \& movement given by doctor in } \\
\text { the prelabor ward }\end{array}$ & Q44,45,46,47,48 \\
\hline Pain relief allowed in the $1^{\text {st }}$ stage & Q49 \\
\hline $\begin{array}{l}\text { Anything else that the lady wanted and whether she was responded to \& } \\
\text { her request allowed }\end{array}$ & Q50 \\
\hline $\begin{array}{l}\text { Before transferring the lady to the DR, notifying her about her progress, } \\
\text { what would be done to her \& instructing her what to do }\end{array}$ & Q52 \\
\hline Privacy in the DR & Q57,64,65 \\
\hline Anesthesia given during delivery & Q75,81 \\
\hline Pain relief during the $2^{\text {nd }}$ stage in the DR & Q92 \\
\hline Informing the lady about the episiotomy procedure & Q113a \\
\hline Cleaning the lady after the delivery, providing a pad \& covering her & Q119,120,121 \\
\hline Giving the baby to the mother for bonding in the DR & Q124 \\
\hline Foot print taking of the baby & Q106d \\
\hline The lady was transferred to the post labor ward accompanied by her baby & Q131 \\
\hline Privacy in the post labor ward & Q133 \\
\hline Welcome, review of data \& communication in the post labor ward & Q134 \\
\hline Instructions to breastfeed the baby & Q135 \\
\hline Eating \& drinking in the post labor ward & Q136,137 \\
\hline The place where the baby was kept in the post labor ward & Q139 \\
\hline $\begin{array}{l}\text { Giving information about the danger signs \& symptoms that may arise } \\
\text { during the post partum period }\end{array}$ & Q150,Q151a-c \\
\hline Giving information about breastfeeding & Q151d-h \\
\hline Giving information about family planning & Q151i,j \\
\hline Giving information about the baby & Q151k,Q152,Q153 \\
\hline Giving information about the danger signs \& symptoms of the newborn & Q154,155 \\
\hline Information given by doctor / nurse & Q156 \\
\hline Information given to the lady in what form & Q157 \\
\hline Antibiotic prescription for the lady & Q161 \\
\hline $\begin{array}{l}\text { Duration that the lady spent in the post labor ward after the delivery until } \\
\text { her discharge }\end{array}$ & Q162 \\
\hline
\end{tabular}


viii

14. Supervision of doctors in training

\begin{tabular}{|l|l|}
\hline Data & Question \# \\
\hline Rank of the provider who delivered the lady & Q78 \\
\hline Rank of the provider who supervised the delivery & Q79 \\
\hline Rank of the provider who repaired the episiotomy & Q113c \\
\hline Rank of the provider who supervised the episiotomy repair & Q113d \\
\hline
\end{tabular}

15. Immediate postpartum care

\begin{tabular}{|l|l|}
\hline Data & Question \# \\
\hline Examining the placenta & Q109 \\
\hline Confirming the uterine contractility & Q110 \\
\hline Episiotomy/ tear repair & Q113,114,115,116 \\
\hline Uterine exploration \& anesthesia & Q117 \\
\hline Cleaning the lady after the delivery, providing a pad \& covering her & Q119,120,121 \\
\hline Giving the baby to the mother for bonding in the DR & Q124 \\
\hline Writing the resuscitation data & Q126 \\
\hline Writing the delivery summary in the file & Q128 \\
\hline
\end{tabular}

16. Postpartum care

\begin{tabular}{|l|l|}
\hline Data & Question \# \\
\hline General exam in the post labor ward & Q140 \\
\hline Postpartum vaginal exam & Q143 \\
\hline Examination of the baby & Q147 \\
\hline Baby's feeding & Q149 \\
\hline $\begin{array}{l}\text { Giving information about the danger signs \& symptoms that may } \\
\text { arise during the post partum period }\end{array}$ & Q150,Q151a-c \\
\hline Giving information about breastfeeding & Q151d-h \\
\hline Giving information about family planning & Q151i,j \\
\hline Giving information about the baby & Q151k,Q152,Q153 \\
\hline $\begin{array}{l}\text { Giving information about the danger signs \& symptoms regarding } \\
\text { the newborn }\end{array}$ & Q154,155 \\
\hline Information given by doctor / nurse & Q156 \\
\hline Information given to the lady in what form & Q157 \\
\hline Antibiotic prescription for the lady & Q161 \\
\hline Providing the lady with a discharge summary & Q159 \\
\hline Discharging doctor's rank & Q160 \\
\hline
\end{tabular}


17. The neonatal care

\begin{tabular}{|l|l|}
\hline Data & Question \# \\
\hline FHS in the ER & Q7 \\
\hline Checking the fetal heart sounds in the 1 $^{\text {st }}$ stage & $\begin{array}{l}\text { Q32 \& Table Q37 on } \\
\text { P46,47 }\end{array}$ \\
\hline Oxytocin administration \& FHS done appropriately & Table Q37 on P46,47 \\
\hline Giving the baby to the mother for bonding in the DR (bonding) & Q124 \\
\hline The provider who received the baby in the DR & Q96 \\
\hline Where was the baby put immediately after the delivery & Q97 \\
\hline Handling of the baby & Q99,100 \\
\hline Baby's health status & Q101 \\
\hline Things done to the baby & Q102,103 \\
\hline Apgar score & Q104 \\
\hline Routine care given to the baby & Q106 \\
\hline Appropriateness of care \& resuscitation & Q107 \\
\hline Encouragement to breastfeed the baby in the post labor ward & Q134g \\
\hline The provider who instructed the lady to breastfeed & Q135b \\
\hline Examination of the baby & Q147 \\
\hline Baby's feeding & Q149 \\
\hline Giving information about the baby & Q151k,Q152,Q153 \\
\hline $\begin{array}{l}\text { Giving information about the danger signs \& symptoms regarding } \\
\text { the newborn }\end{array}$ & Q154,155 \\
\hline
\end{tabular}

18. Discharge procedure

\begin{tabular}{|l|l|}
\hline Data & Question \# \\
\hline Medications prescribed for the mother before discharge & Q161 \\
\hline The rank of the provider who discharged the lady & Q160 \\
\hline Providing the lady with a discharge summary & Q158,159 \\
\hline Range of hours between delivery \& the discharge of the woman & Q93 \& Q162 \\
\hline Time between the delivery \& discharge was acceptable & Q163 \\
\hline
\end{tabular}



APPENDIX C

EXAMPLES OF FINDINGS 
These charts represent a small proportion of the findings generated by the checklist. They are included here to illustrate the kind of data such an approach can provide.

Figure 1

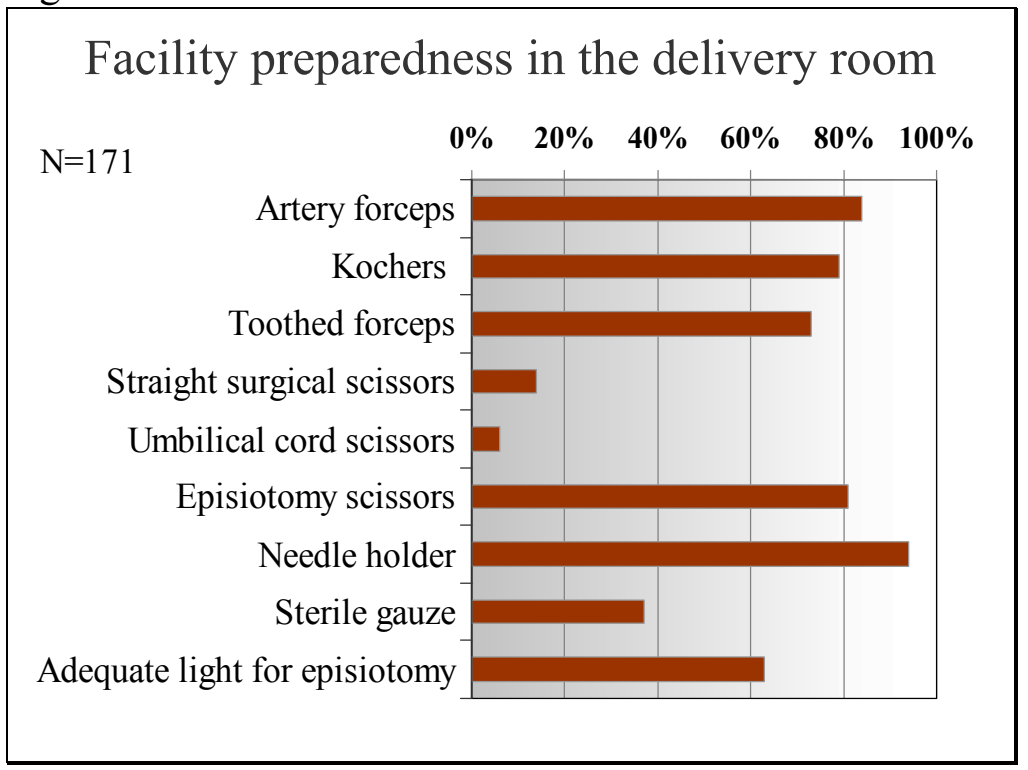

Facility preparedness was acceptable, with the exception of the straight surgical scissors and the umbilical cord scissors. (Data from Q85)

Figure 2

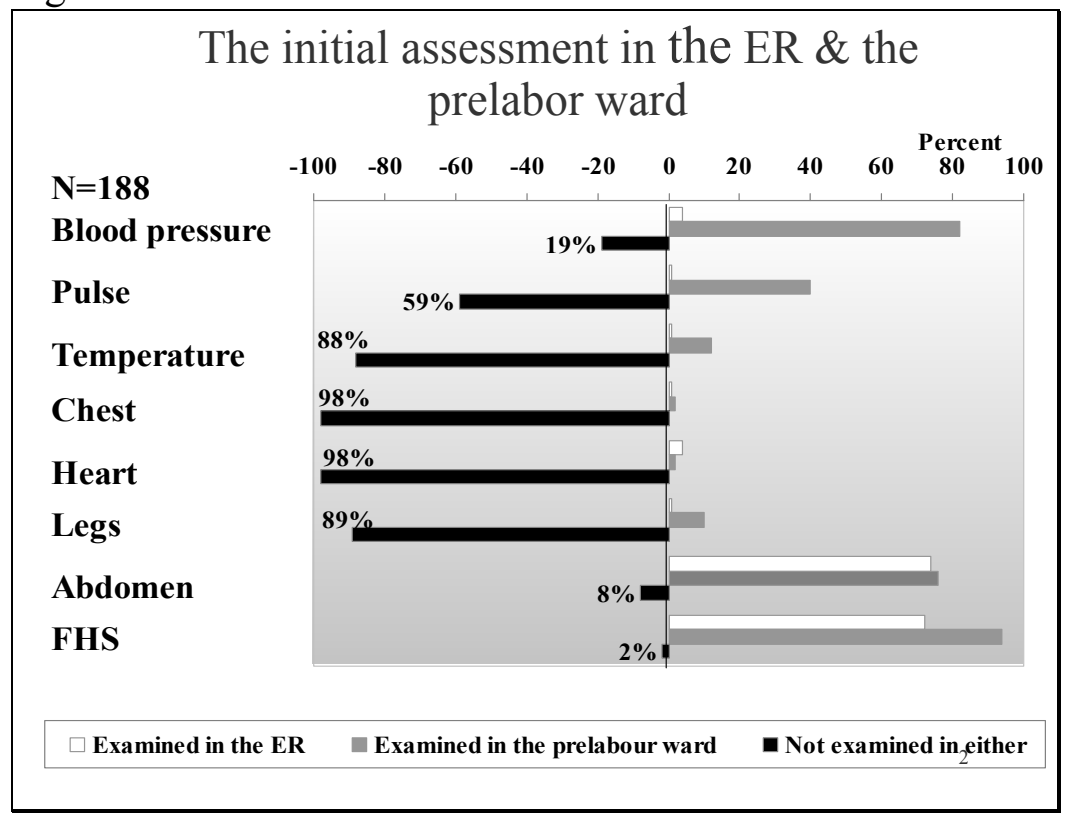

The bars on the right show the proportions of women for whom these items were checked, in the emergency room (ER) in white or in the prelabor ward in grey. The black bars on the left show the proportions of women for whom the items were not checked in either. Ward.

(Data from Q5, 6, 7, 30, 31) 
Figure 3

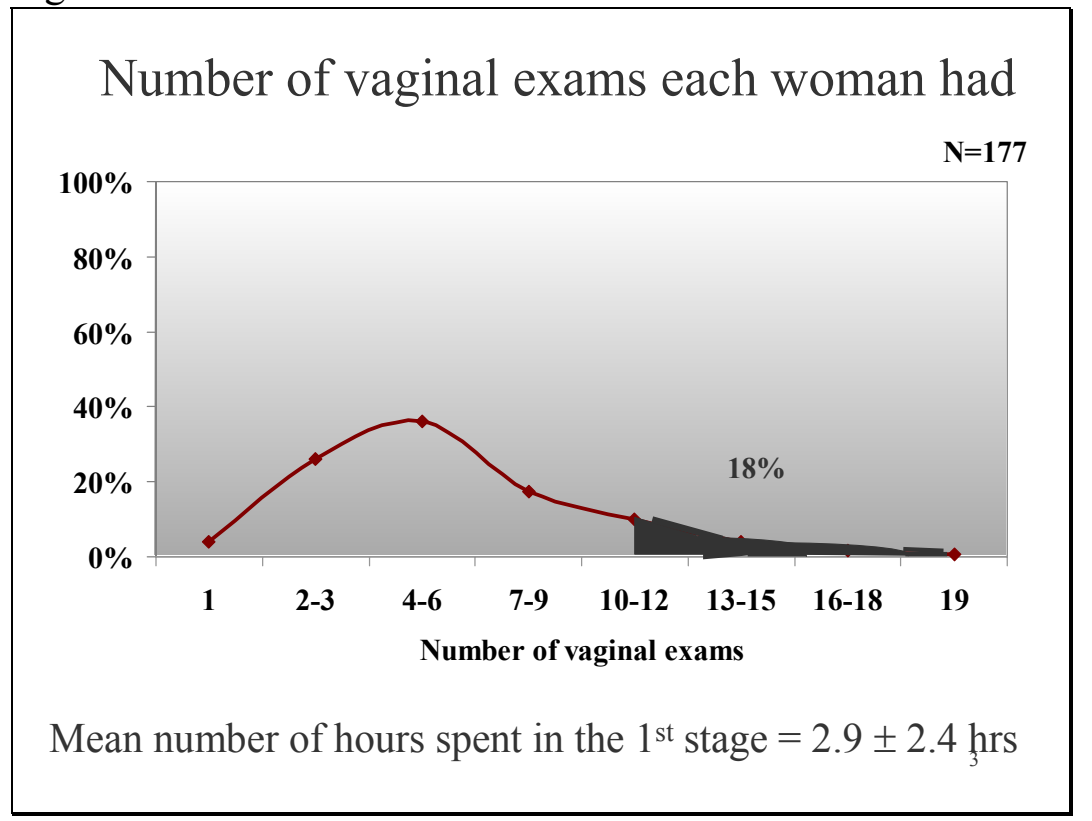

Almost one-fifth (18\%) of the women had 10 or more vaginal exams during their stay.

(Data from Table Q33 on P40-45)

Figure 4

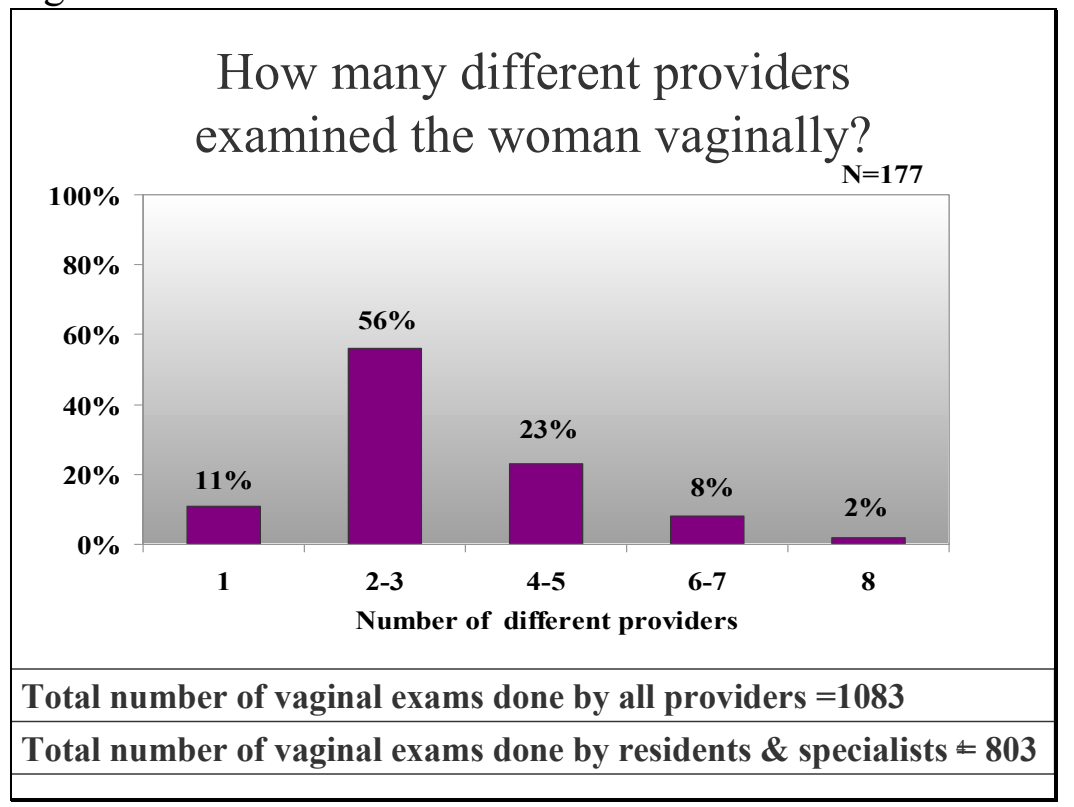

One-third $(33 \%)$ of the observed women were examined by 4 or more different providers.

Note: examinations conducted by junior doctors in training were excluded. This data is based on 803 vaginal exams performed by the managing provider. (Data from Q55) 
Figure 5

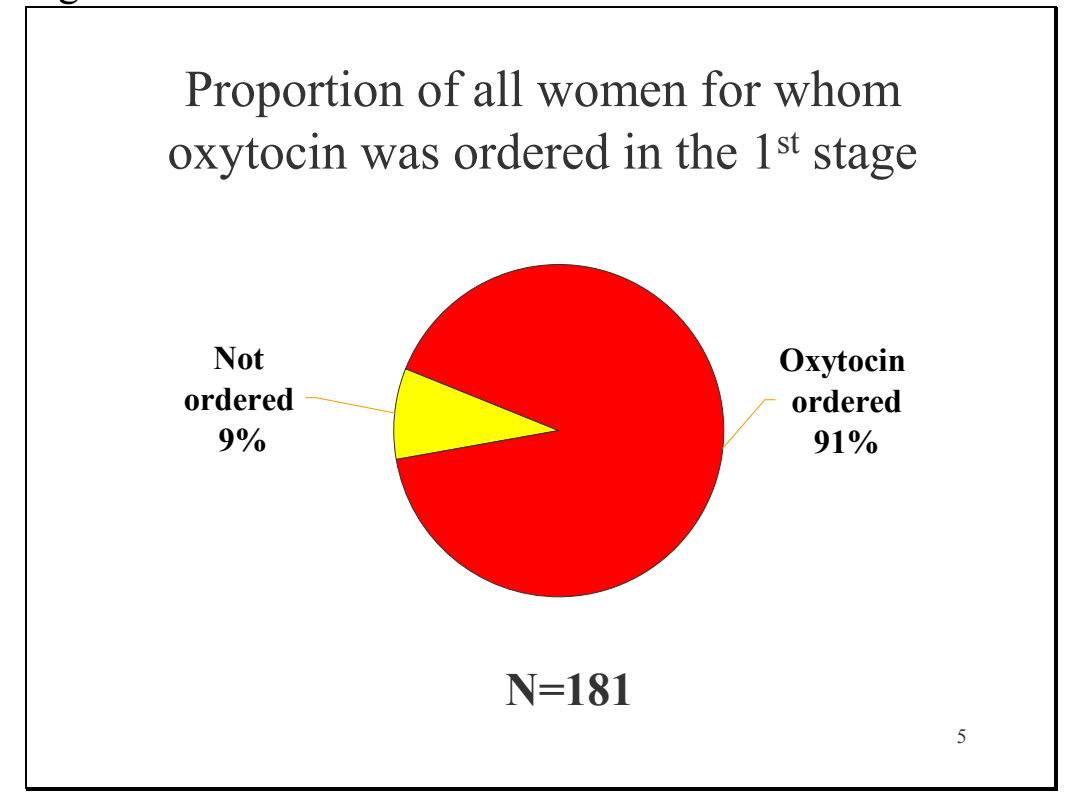

Figure 6

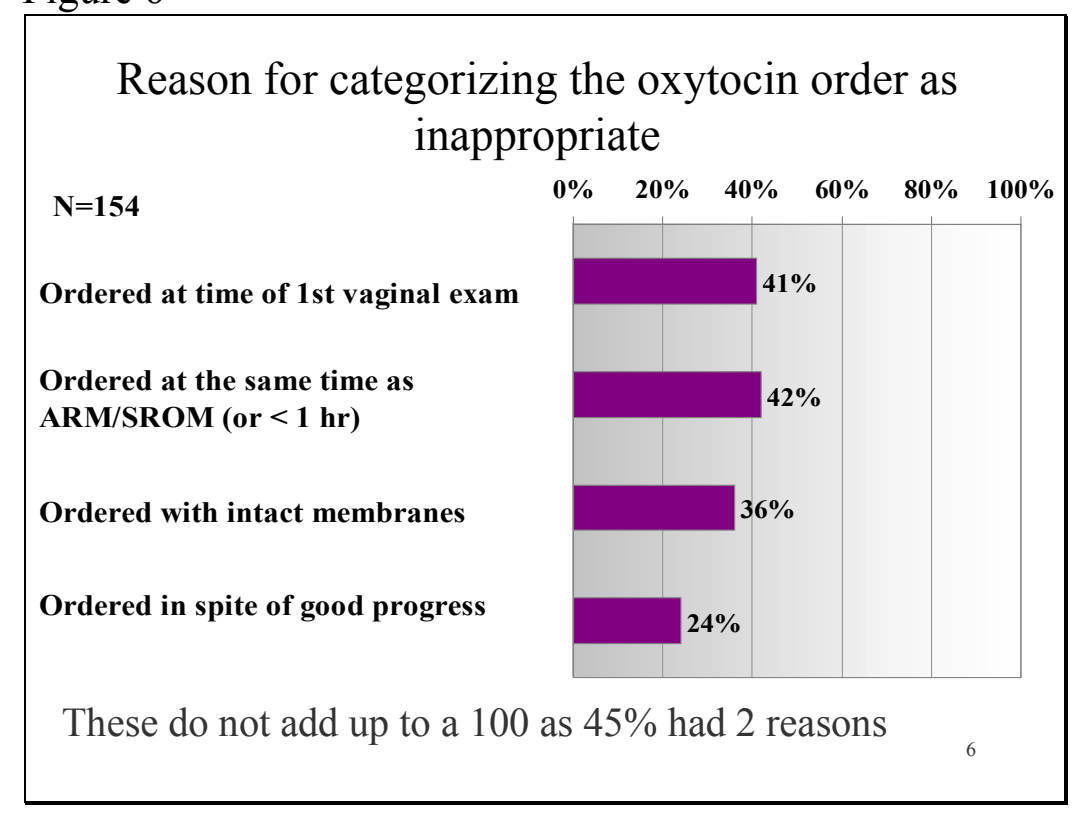

Labor was augmented with oxytocin in $91 \%$ of the labors observed.

(Data from Table Q37 on P46,47)
Augmented labors were mostly inappropriately done. Figure 6 shows the reasons for inappropriateness.

(Data from Q41 \& Table Q37 on $\mathrm{P} 46,47$ ) 
Figure 7

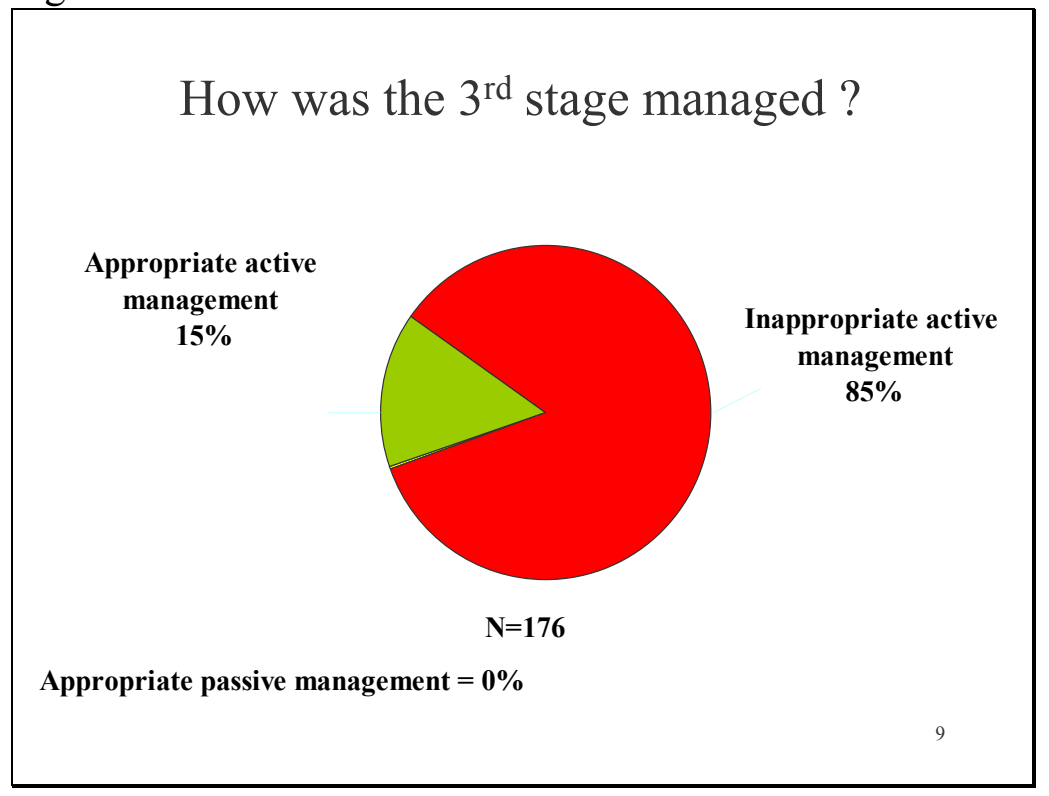

The third stage of labor was largely inappropriately managed.

Passive management was not done.

(Data from Q94, 95 \& Table Q37 on P46,47)

Figure 8

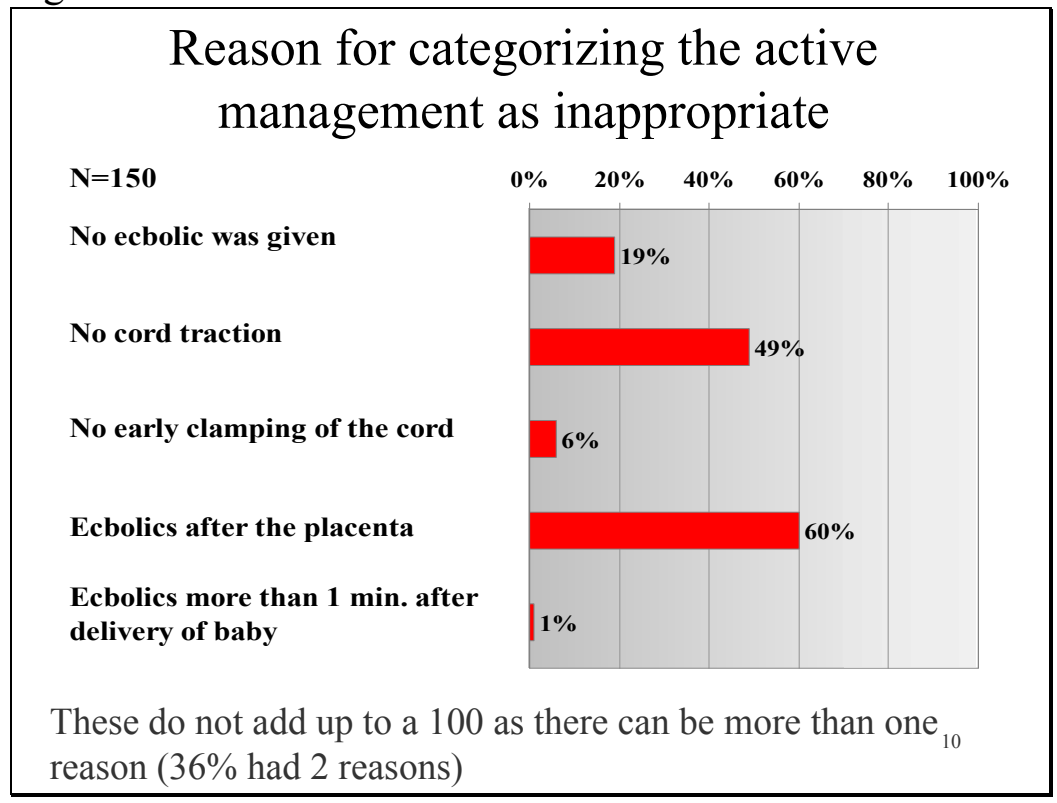

Management of the $3^{\text {rd }}$ stage was inappropriate in $85 \%$ of the observed deliveries. Reasons for inappropriateness are shown in Figure 8. (Data from Q94, 95 \& Table Q37 on P46,47) 
Figure 9

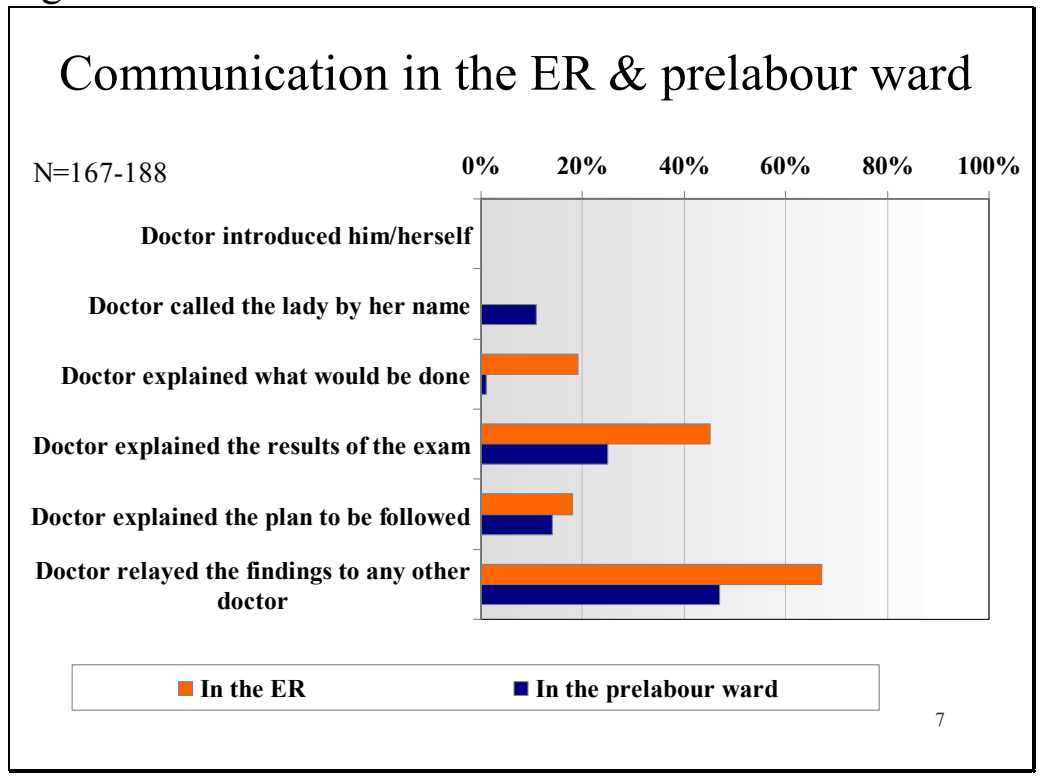

Provider-patient

communication was generally poor.

(Data from Q4, 8, 10, 23, 24, 26, 34) 



\section{Monographs in Reproductive Health}

No. 1• Hind Khattab

Women's Perception of Sexuality in Rural Giza, 1996

No. 2• Hania Sholkamy

Women's Health Perceptions: A Necessary Approach to an Understanding of

Health and Well-Being, 1996

No. 3• Farha Ghannam

The Social Construction of the Female Body in Low-Income Cairo, 1997

No. 4• Rita Giacaman and Muna Odeh

Women's Perceptions of Health and Illness in the Context of National Struggle in the Old City of Nablus, Palestine, 2002

\section{Policy Series in Reproductive Health}

No. 1• Huda Zurayk, Nabil Younis, Hind Khattab

Rethinking Family Planning Policy in Light of Reproductive Health Research, 1994 (in Arabic 1995)

No. 2• Nabil Younis, Karima Khalil, Huda Zurayk, Hind Khattab Learning about the Gynecological Health of Women, 1994 (in Arabic 1995)

No. 3• Hind Khattab, Huda Zurayk, Nabil Younis, Olfia Kamal

Field Methodology for Entry into the Community, 1994 (in Arabic 1995)

No. 4 - Hind Abou-Seoud Khattab, Huda Zurayk, Olfia Ibrahim Kamal, Francoise Ghorayeb, Nadine Karraze Chorbagi An Interview-Questionnaire on Reproductive Morbidity: The Experience of the Giza Morbidity Study, 1997

No. 5• Raeda Al-Qutob, Salah Mawajdeh, Laila Nawar, Salama Saidi, Firas Raad Assessing the Quality of Reproductive Health Services, 1998

No. 6• Karima Khalil, Abdel Moneim Farag, Assem Anwar, Dina Galal, Olfia Kamal, Nadine Karraze Shorbagi, Miral Breebaart, Hind Khattab, Nabil Younis and Huda Zurayk

Integrating an RH Framework within Primary Care Services: The Experience of the RH Intervention Study, 2000.

No. 7• Abdel Moneim Farag, Karima Khalil, Assem Anwar, Dina Galal, Nabil Younis Improving Women's Reproductive Health: The Medical Components of a Primary Level Framework of Services. The Experience of the Reproductive Health Intervention Study, 2002. 